\title{
Sypramolecular Compounds as Precursors of Active Carbon (Review)
}

Yulia V. Tamarkina*, Vladimir A. Kucherenko and Tatiana G. Shendrik Institute of Physical and Organic Chemistry and Coal Chemistry NAS 70 R. Luxemburg Str., Donetsk, 831114, Ukraine

Received 22.12.2014, received in revised form 10.01.2015, accepted 21.02.2015

Review of own and literature data, considering coal and products of coal reactions with different chemicals as supramolecular compounds of coal (SMC) was performed. Considered approaches to coal processing into porous carbon materials (PCM) include two main stages - the transformation of initial or modified coal into SMC by means of intercalation with alkali metals hydroxides and the following thermochemical conversion into PCM.

Analysis of literature data showed that the new methods of coal conversion into PCM are based on the following options: 1) formation of SMC with $\mathrm{KOH}$ (or $\mathrm{NaOH}$ ) and following thermolysis in an inert atmosphere at $\leq 900^{\circ} \mathrm{C}$; 2) chemical modification of coal and following carbonization and physical activation by $\mathrm{CO}_{2}$ or steam at $\leq 1000{ }^{\circ} \mathrm{C}$; 3) coal intercalation by acids-oxidizers $\left(\mathrm{H}_{3} \mathrm{NO}_{3}\right.$, etc.) and following treatment at conditions of heat stroke.

Mechanism of SMC formation at treatments of coals with different degree of metamorphism by $\mathrm{HNO}_{3}-\mathrm{Ac}_{2} \mathrm{O}$ mixture was discussed. The ability of coal to form SMC depends on the degree of coal metamorphism and the maximum ability have the coals with $C^{d a f}=87-90 \%$. Supramolecular compounds of coal with $\mathrm{KOH}$ transform into high porosity carbon materials after thermal treatment at $800{ }^{\circ} \mathrm{C}$.

Keywords: coal, chemical modification, supramolecular compounds, thermal treatments, porous carbon.

(c) Siberian Federal University. All rights reserved

* Corresponding author E-mail address: y_tamarkina@rambler.ru 


\title{
Супрамолекулярные соединения
}

\section{в качестве предшественников активных углей (обзор)}

\author{
Ю.В. Тамаркина, \\ В.А. Кучеренко, Т.Г. Шендрик
}

Институт физико-органической химии и углехимии им. Л.М. Литвиненко Национальной академии наук Украинь Украина, 83114, Донеик, ул. Р. Люксембург, 70

Выполнен обзор литературных и собственных данных авторов, рассматриваюших ископаемые угли и продукты их реакций с различными вещзествами как супрамолекулярные соединения угля (СМС). Подходы к переработке ископаемых углей в пористые углеродные материаль (ПУМ) включают две основнье стадии - трансформацию угля (исходного или модифицированного) в СМС за счет интеркалирования гидроксидами щзелочных металлов и последующую термохимическую конверсию СМС в ПУМ. Анализ литературных данных показал, что новые способы конверсии угля в ПУМ основаны на следующчих вариантах: 1) образование СМС с КОН (или NaOH) и последуюший термолиз в интертной атмосфере при $\leq 900{ }^{\circ} \mathrm{C}$; 2) химическая модификаџия угля и последующче карбонизаџия и «физическая» активаџия СО или паром при $\leq 1000{ }^{\circ} \mathrm{C}$; 3) интеркалирование в уголь кислот-окислителей (HNO и др.) и последующая обработка в условиях теплового удара.

Рассмотрен механизм образования СМС при обработке углей разной степени метаморфизма смесью $\mathrm{HNO}_{3}-\mathrm{Ac}_{2} \mathrm{O}$. С ростом степени метаморфизма способность угля образовывать соединения включения угля изменяется экстремально с максимумом для углей с $C^{\text {daf }}=87-90 \%$. Супрамолекулярные соединения угля с КОН превращуаются в высокопористые углеродные материаль в результате термообработки при $800{ }^{\circ} \mathrm{C}$.

Ключевые слова: ископаемый уголь, химическая модификация, супрамолекулярные соединения, термообработка, пористый углерод.

\section{Введение}

Изучение реакций угля с позиций супрамолекулярной химии [1] - новое направление углехимии. Первым системным исследованием, по-видимому, является международный проект «Molecular Engineering of Coal: Supramolecular Structure and Novel Utilization Technology» (1996-2000) [2], рассматривающий уголь и продукты его реакций с различными веществами как супрамолекулярные соединения (CMC). В то же время частные случаи СМС - молекулярные комплексы «гость-хозяин» и соединения включения как структурные аналоги угля и некоторых угольных продуктов привлечены в углехимию достаточно давно. Это «двухфазная модель» [3] структуры углей, рассмотрение строения «соленого» угля как природно сформированного комплекса «гость-хозяин» [4], соединения включения углей (СВУ) как продуктов реакций со щелочными металлами и их галогенидами [5], а также окислителями $\left(\mathrm{Br}_{2}, \mathrm{HNO}_{3}\right.$, 
$\mathrm{HClO}_{4}$, и др.) [5-10]. Подходы к формированию СМС с последующей их конверсией в химические продукты также реализованы при импрегнировании углей щелочами [11], получении гуматов щелочных металлов [12] и адсорбентов на основе углерода [13-15].

В целом направление перспективно, но находится в начальной стадии накопления экспериментальных данных и разработки подходов к получению и исследованию СМС. Получение СМС осуществляют главным образом в процессе низкотемпературной $\left(15-30{ }^{\circ} \mathrm{C}\right)$ химической модификации угля, подобной процессам интеркалирования [16] или образования молекулярных комплексов «гость - хозяин» [17]. Трансформация угля в СМС с реагентами или катализаторами является потенциально эффективным подходом к повышению активности угольного сырья во многих термохимических процессах.

В данной работе развит подход к переработке ископаемых углей, который предусматривает две основные стадии: 1) трансформацию угля (исходного или модифицированного окислением) в СМС за счет интеркалирования гидроксидов щелочных металлов и 2) термохимическую конверсию СМС в активированные угли (АУ).

Принудительное интеркалирование КОН в бурый уголь приводит к образованию СМС, в котором ионы $\mathrm{K}^{+}, \mathrm{OH}^{-}$и молекулы $\mathrm{KOH}$ включены в полости пространственного каркаса угля и фиксируются в нем нековалентными связями [11]. При нагревании этих соединений $\left(\leq 900{ }^{\circ} \mathrm{C}\right.$, $\leq 2$ ч) их угольный каркас превращается в АУ с величиной удельной поверхности $\mathrm{S}_{\mathrm{BET}} \leq 1000 \mathrm{M}^{2} /$ г. Окислительная модификация угля способствует образованию СМС с $\mathrm{KOH}$ и улучшает его конверсию в адсорбенты, что экспериментально установлено на гумолитах [13] и сапропели$\operatorname{Tax}[14,18]$.

Интеркалирование антрацита в $\mathrm{NO}_{2}{ }^{+}$- и $\mathrm{NO}^{+}$- содержащих системах $\left(\mathrm{HNO}_{3}, \mathrm{HNO}_{3}-\mathrm{Ac}_{2} \mathrm{O}\right.$, $\mathrm{NaNO}_{2}-\mathrm{H}_{2} \mathrm{SO}_{4}, 20-80{ }^{\circ} \mathrm{C}$ ) реформирует его структуру и дает материал с существенно большей активностью по отношению к водяному пару $\left(700-900{ }^{\circ} \mathrm{C}\right)$ [15]. Образование антрацитом СМС типа «гость - хозяин» реализуется в небольшой степени, касаясь лишь аморфной части угля, но ускоряет образование АУ с $\mathrm{S}_{\mathrm{BET}}=800-1000 \mathrm{~m}^{2} / \Gamma$.

Интеркалирование угля в системе $\mathrm{HClO}_{4}(70 \%)-\mathrm{H}_{2} \mathrm{O}(30 \%)$ при $120-170{ }^{\circ} \mathrm{C}(2-4$ ч) использовано $[7,8]$ как первая стадия получения высокопористых адсорбентов из антрацита. Известно [16], что $\mathrm{HClO}_{4}$ - сильный электроноакцептор и в реакции с графитом окисляет его полиареновые слои до катионов, а анионы $\mathrm{ClO}_{4}^{-}$интеркалируются в графитовую матрицу. Такой путь, возможно, реализуется и в системе «антрацит- $\mathrm{HClO}_{4}$ », но дополнительно сопровождается оксидеструкцией алифатических и части ароматических структурных фрагментов антрацита. Как следствие, образуются газы $\mathrm{CO}$ и $\mathrm{CO}_{2}$, а также карбоксильные, хиноидные и эфирные группы, для которых донором О-атомов являются внутрирешеточные анионы $\mathrm{ClO}_{4}{ }^{-}$и молекулы $\mathrm{HClO}_{4}$. Так же идентифицированы фрагменты со связями $\mathrm{C}_{\mathrm{ar}}-\mathrm{Cl}$ и ионы $\mathrm{Cl}^{-}$как продукты многоэлектронного восстановления хлорной кислоты $[7,8]$. Вызванная такими реакциями реорганизация структуры антрацита способствует развитию ультрамикропор ( $\leq 0,4$ нм) и дополнительных каналов диффузии активирующего агента $\left(\mathrm{CO}_{2}\right)$.

Для синтеза СМС хлорная кислота использована как компонент тройной системы $\mathrm{HClO}_{4}$ $\mathrm{HNO}_{3}-\mathrm{H}_{2} \mathrm{O}$ [9] в условиях $\left(20^{\circ} \mathrm{C}, 8\right.$ ч), аналогичных синтезу графитовых соединений интеркалирования, которые при термоударе $\left(700-1200^{\circ} \mathrm{C}\right)$ переходят в более пористый материал термографенит [16]. Полученные таким образом СМС подробно не исследованы. Выявлено 
$[9,10]$, что сочетание интеркалирования и термоудара $\left(700{ }^{\circ} \mathrm{C}, \leq 5 \mathrm{c}\right)$ переводит один уголь (Cdaf $91,9 \%$; Вьетнам) в материал с высокой поверхостью $\mathrm{S}_{\mathrm{BET}}=520 \mathrm{~m}^{2} \cdot \Gamma^{-1}$; а другой уголь ( $\mathrm{C}^{\mathrm{daf}}$ 91,9\%; Франция) нечувствителен к термоудару $\left(\mathrm{S}_{\mathrm{BET}}=10-20 \mathrm{M}^{2} \cdot \Gamma^{-1}\right)$. Можно предположить, что структура первого угля максимально подготовлена к интеркалированию в системе $\mathrm{HClO}_{4}-\mathrm{HNO}_{3}-\mathrm{H}_{2} \mathrm{O}$, и, как следствие, при термоударе СМС наблюдаются эффекты, которые характерны для СИГ.

Анализ литературных данных [19] показал, что новые способы конверсии угля в АУ сфокусированы на трех вариантах: 1) образование $\mathrm{CMC} \mathrm{c} \mathrm{KOH}$ (или $\mathrm{NaOH}$ ) с последующим термолизом ( $\leq 900^{\circ} \mathrm{C}, \leq 2$ ч, в инертной атмосфере); 2) химическая модификация угля в режиме интеркалирования с последующей карбонизацией и «физической» активацией $\left(\mathrm{CO}_{2}, \mathrm{H}_{2} \mathrm{O}, \leq 1000{ }^{\circ} \mathrm{C}\right)$; 3) интеркалирование в уголь кислот-окислителей с последующим скоростным нагревом - термоударом. Можно считать установленным, что интеркалирование (химическая модификация) угля, формирование $\mathrm{CMC} \mathrm{c} \mathrm{KOH}$ (или окислителями) и их термолиз в различных газовых средах являются высокоэффективными стадиями конверсии углей в адсорбенты. В то же время закономерности образования и термолиза СМС из угля разной степени метаморфизма (CM), a также свойства СМС и продуктов их термолиза изучены явно недостаточно.

\section{Структурные превращения угля при интеркалировании}

Низкотемпературное $\left(20^{\circ} \mathrm{C}\right)$ интеркалирование угля разной СМ выполняли обработкой эквимолярной смесью $\mathrm{HNO}_{3}-\mathrm{Ac}_{2} \mathrm{O}[20,21]$, в которой количественно образуется ацетилнитрат $\left(\mathrm{HNO}_{3}+\mathrm{Ac}_{2} \mathrm{O} \rightarrow \mathrm{NO}_{2} \mathrm{AcO}+\mathrm{AcOH}\right)$. В контакте с углем ацетилнитрат диссоцирует $\left(\mathrm{NO}_{2} \mathrm{AcO}\right.$ $\left.\leftrightarrow \mathrm{NO}_{2}{ }^{+}+\mathrm{AcO}^{-}\right)$, катионы нитрония окисляют угольные полиарены $\mathrm{C}_{\mathrm{n}}$ до катион-радикалов $\left(\mathrm{C}_{\mathrm{n}}\right.$ $+\mathrm{NO}_{2} \rightarrow \mathrm{C}_{\mathrm{n}}^{+\cdot}+\mathrm{NO}_{2}{ }^{2}$, ацетат-анионы интеркалируются в уголь и нейтрализуют позитивный заряд. Параллельно коинтеркалируются молекулы уксусной кислоты. С феноменологической точки зрения такая модель образования СМС идентична модели образования акцепторных соединений интеркалирования графита [6] и описывается упрощенным уравнением:

$$
\mathrm{C}_{\mathrm{n}}+\mathrm{NO}_{2} \mathrm{AcO}+\mathrm{zAcOH} \rightarrow \mathrm{Cn}^{+} \cdot \mathrm{AcO}^{-} \cdot \mathrm{zAcOH}+\mathrm{NO}_{2} .
$$

Угольное соединение включения является радикалом и может окисляться с образованием дикатиона:

$$
\mathrm{Cn}^{+} \cdot \mathrm{AcO}^{-} \cdot \mathrm{zAcOH}+\mathrm{NO}_{2} \mathrm{AcO} \rightarrow \mathrm{Cn}^{+\cdot}\left(\mathrm{AcO}^{-}\right)_{2} \cdot \mathrm{zAcOH}+\mathrm{NO}_{2}
$$

Также возможны реакции присоединения, электрофильного замещения и оксидеструкции органического угольного каркаса.

Взаимодействие в системе «уголь- $\mathrm{HNO}_{3}-\mathrm{Ac}_{2} \mathrm{O}$ » сопровождается выделением $\mathrm{NO}_{2}$, набуханием угля, а также изменением его веса $(\Delta \mathrm{m}, \%)$, принятого как количественная мера глубины структурной модификации при заданном времени $(\tau)$, соотношении реагент/уголь $(\mathrm{R}, \mathrm{Moль} / \mathrm{\kappa}$ ) и содержании углерода ( $\left.\mathrm{C}^{\mathrm{daf}}, \%\right)$. Изменение веса любого угля в ходе реакции описывается кривой с максимумом, как на рис. 1, или с выходом на плато, приближаясь к определенному «стационарному» значению $\Delta \mathrm{m}$, обусловленному природой угля $[22,23]$. Кроме изменения веса также наблюдается набухание угля: относительное увеличение объема $\left(\mathrm{V} / \mathrm{V}_{0}\right)$ является функцией СМ. 

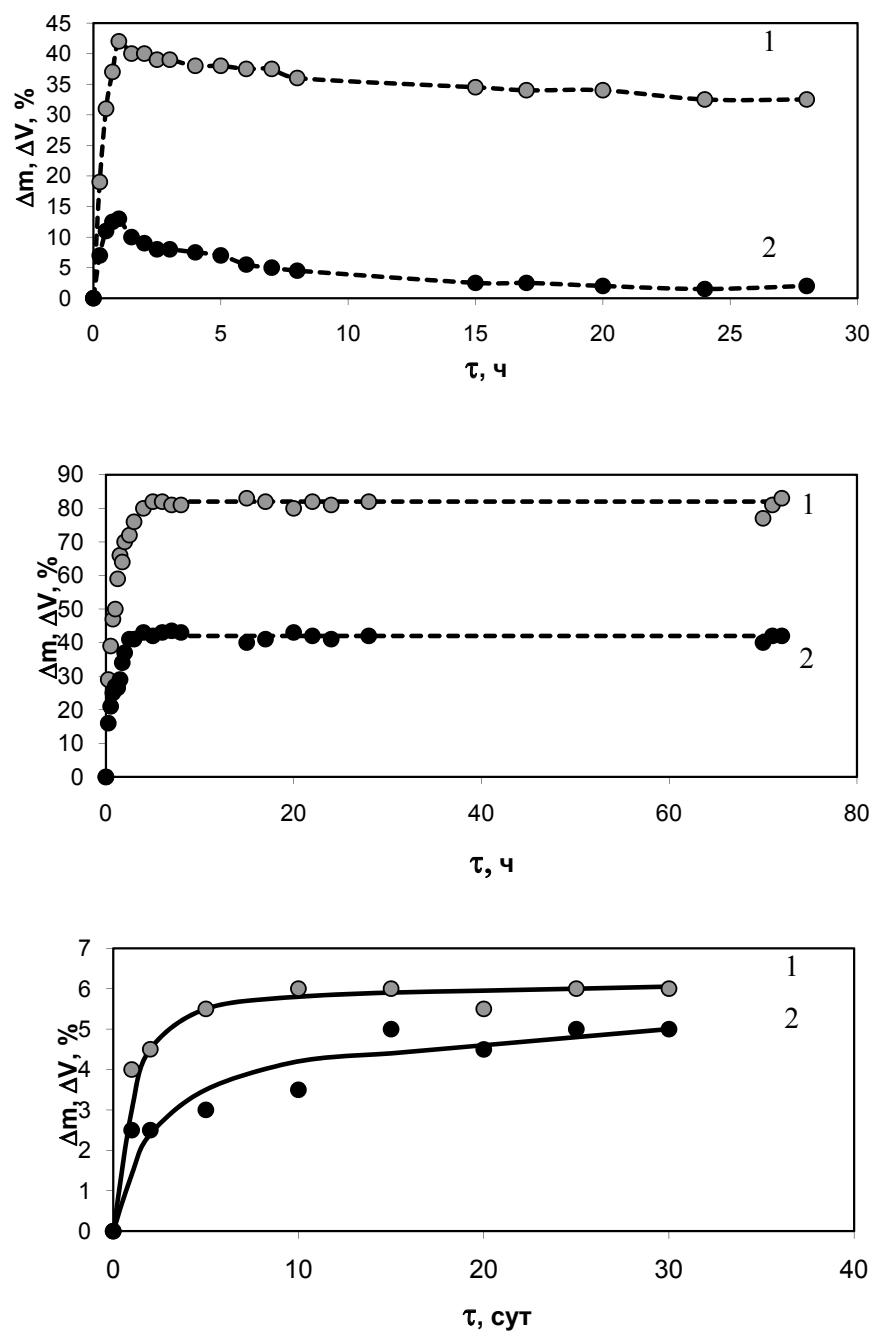

Рис. 1. Прирост объема (1) и массы (2) угля Д ( $\left.\mathrm{C}^{\mathrm{daf}} 80,0 \%\right), \mathrm{K}_{2}\left(\mathrm{C}^{\mathrm{daf}} 88,6\right.$ \%) и антрацита $\mathrm{A}_{1}\left(\mathrm{C}^{\mathrm{daf}} 93,3\right.$ \%) при взаимодействии со смесью $\mathrm{HNO}_{3}-\mathrm{Ac}_{2} \mathrm{O}\left(\mathrm{R}_{\mathrm{ox}}=100\right.$ моль'кГ-1)

Величины $\Delta \mathrm{m}$ и $\Delta \mathrm{V}$ зависят от соотношения $\mathrm{R}_{\text {ох }}$ (рис. 2). Для низкометаморфизованного угля (марка Д, $\left.\mathrm{C}^{\mathrm{daf}} 80,0 \%\right) \Delta \mathrm{m}$ и $\Delta \mathrm{V}$ изменяются экстремально [24], причем значения группируются в узком интервале. Четко различаются область I (увеличение $\Delta \mathrm{m}$ и $\Delta \mathrm{V}$ при $\mathrm{R}_{\mathrm{ox}} \leq 20 \mathrm{Moль} \mathrm{F}^{-1}$ ) и область II ( $\mathrm{R}_{\text {ox }} \geq 20$ моль кг $\left.{ }^{-1}\right)$, что характеризуется снижением величин $\Delta \mathrm{m}$ и $\Delta \mathrm{V}$ и их приближением к стационарным значениям $\Delta \mathrm{V}=62 \pm 2 \%$ и $\Delta \mathrm{m}=70 \pm 2 \%$. В области I уголь быстро (минуты) и полностью поглощает реагент, что сопровождается набуханием, выделением $\mathrm{NO}_{2}$ и исчезновением жидкой фазы; уголь становится визуально сухим. В области II жидкая фаза наблюдается в течение всего времени реакции ( $\tau=24$ ч). Если предположить, что весь реагент количественно интеркалируется в уголь по реакции $\mathrm{C}_{\mathrm{n}}+\mathrm{NO}_{2}{ }^{+} \mathrm{Ac}^{-} \rightarrow \mathrm{C}_{\mathrm{n}}^{+} \mathrm{AcO}^{-}+\mathrm{NO}_{2}$, то зависимость $\Delta \mathrm{m}-\mathrm{R}_{\text {ох }}$ будет передаваться прямой линией на рис. 2а. Превышение экспериментальных данных над расчетными свидетельствует о протекании других реакций, например химической модификации угля и коинтеркалирования молекул АсОН. 

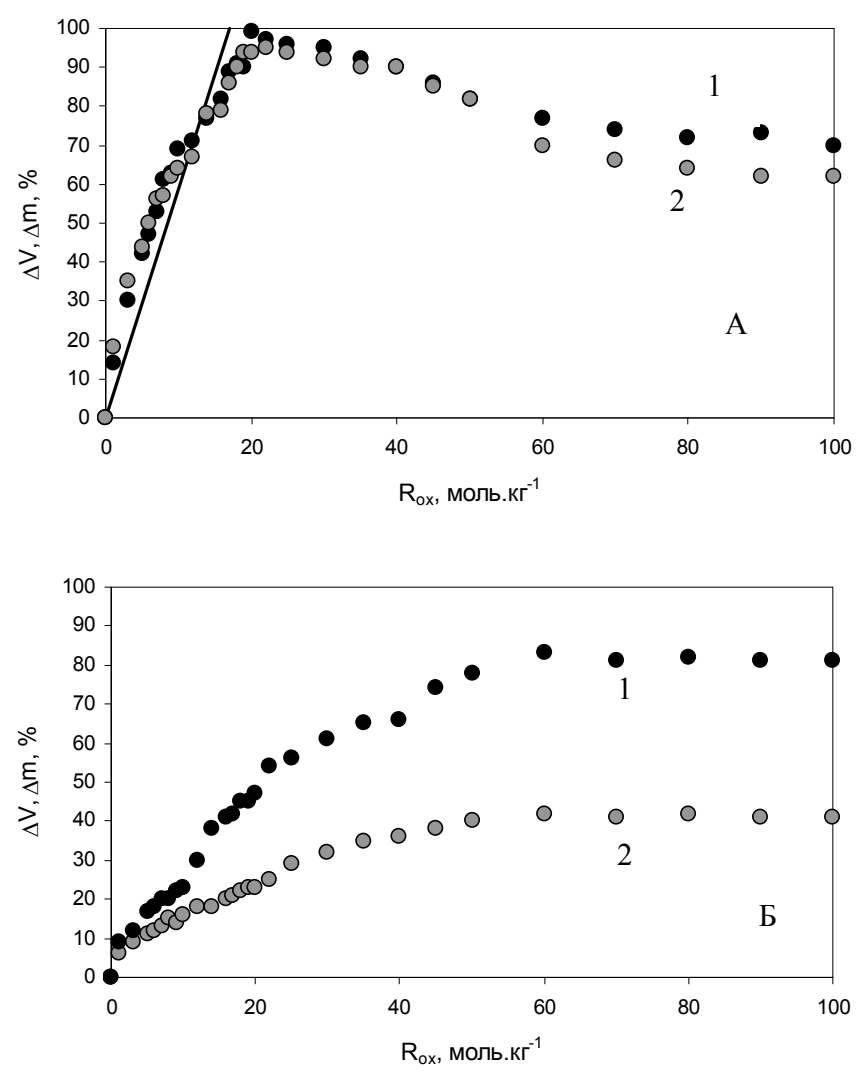

Рис. 2. Зависимости $\Delta \mathrm{V}(1)$ и $\Delta \mathrm{m}(2)$ от соотношения $\mathrm{R}_{\text {ох }}$ для угля Д (А) и $\mathrm{K}_{2}$ (Б) [24]

Изменение $\Delta \mathrm{m}$ и $\mathrm{V} / \mathrm{V}_{0}$ и выделение $\mathrm{NO}_{2}$ практически завершаются за 18-24 ч, и уголь полностью реорганизуется в новое угольное вещество - структурно-модифицированный уголь, обозначенный как СМС.

Глубина модификации экстремально зависит от СМ, как видно из рис. 3: максимальные $\Delta \mathrm{m}$ показывают уголь средней $\mathrm{CM}\left(\mathrm{C}^{\mathrm{daf}} 90 \pm 2 \%\right)$. Увеличение веса обусловлено внедрением и присоединением реакционных частиц к каркасу, что вызывает реорганизацию надмолекулярной и молекулярной структуры угля.

Интеркалирование частиц-гостей приводит к изменениям надмолекулярной структуры угля (табл. 1), установленных методом рентгеноструктурного анализа (РСА) [25]. Межслоевые расстояния в «кристаллитах» СМС больше, чем у исходного угля, и только для антрацитов $\left(\mathrm{C}^{\mathrm{daf}}=93,3-95,2 \%\right)$ они приблизительно одинаковы. Общая тенденция снижения параметра $\mathrm{d}_{002}$ с ростом СМ исходного угля сохраняется и для $\mathrm{CMC}$. Как видно на рис. 4 , высота $\left(\mathrm{L}_{\mathrm{c}}\right)$ и диаметр $\left(\mathrm{L}_{\mathrm{a}}\right)$ «кристаллитов» угля монотонно увеличиваются с ростом $\mathrm{C}^{\mathrm{daf}}$; характер зависимостей (линии 1 и 4) приблизительно совпадает с данными других исследований надмолекулярной структуры угля Донецкого бассейна [26]. Обработка угля смесью $\mathrm{HNO}_{3}-\mathrm{Ac}_{2} \mathrm{O}$ при $\mathrm{R}_{\mathrm{ox}}=20$ моль кг-1 приводит к увеличению высоты $\mathrm{L}_{\mathrm{c}}$ (рис. 4 , линия 2).

При большем соотношении $\mathrm{R}_{\mathrm{ox}}=50$ моль к $^{-1}$ изменения надмолекулярной структуры более заметны. Как видно на рис. 4 , линии 3 и 6 , значения $\mathrm{L}_{\mathrm{c}}$ и $\mathrm{L}_{\mathrm{a}}$ уменьшаются, причем особенно 


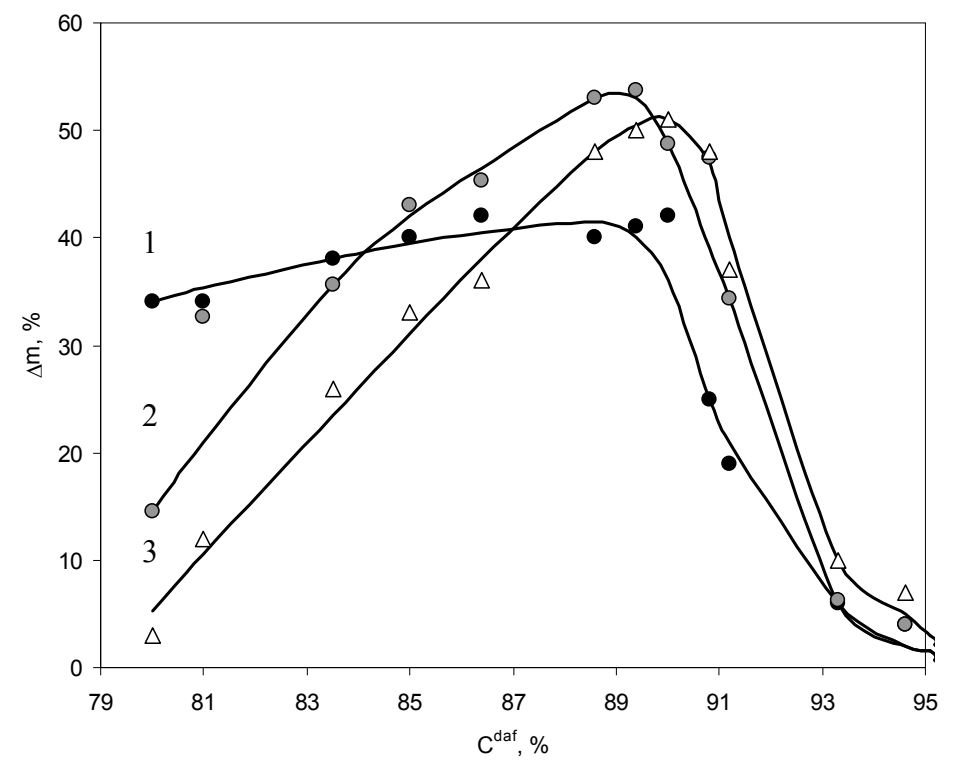

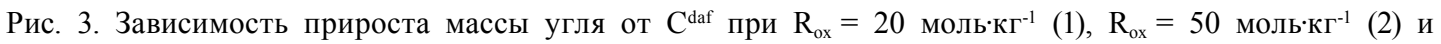
$\mathrm{R}_{\mathrm{ox}}=100$ моль $\cdot к \Gamma^{-1}(3)$

Таблица 1. Структурные параметры углей и твердых продуктов их взаимодействия со смесью $\mathrm{HNO}_{3}-$ $\mathrm{Ac}_{2} \mathrm{O}$

\begin{tabular}{|c|c|c|c|c|c|c|c|c|c|c|}
\hline \multirow{2}{*}{ Образец } & \multirow{2}{*}{$C^{\text {daf }}, \%$} & \multicolumn{3}{|c|}{$\mathrm{d}_{002, \mathrm{HM}}$} & \multicolumn{3}{|c|}{$\mathrm{L}_{\mathrm{c}}, \mathrm{HM}$} & \multicolumn{3}{|c|}{$\mathrm{L}_{\mathrm{a}}, \mathrm{HM}$} \\
\hline & & уголь & $\mathrm{CBY}^{1)}$ & $\mathrm{CBY}^{2)}$ & уголь & $\mathrm{CBY}^{1)}$ & $\mathrm{CBY}^{2)}$ & уголь & $\mathrm{CBY}^{1)}$ & $\mathrm{CBY}^{2)}$ \\
\hline БУ & 70,4 & 0,416 & 0,448 & 0,439 & 0,78 & 0,88 & 0,41 & 1,39 & 1,19 & 0,55 \\
\hline KAУ & 73,7 & 0,412 & 0,451 & 0,437 & 0,80 & 0,91 & 0,43 & 1,46 & 1,31 & 0,55 \\
\hline Д & 80,0 & 0,407 & 0,447 & 0,436 & 0,87 & 0,99 & 0,47 & 1,68 & 1,64 & 0,56 \\
\hline$\Gamma_{1}$ & 81,0 & 0,417 & 0,450 & 0,435 & 0,84 & 0,94 & 0,47 & 1,54 & 1,52 & 0,56 \\
\hline$\Gamma_{2}$ & 83,5 & 0,395 & 0,438 & 0,410 & 0,89 & 1,03 & 0,48 & 1,59 & 1,59 & 0,57 \\
\hline Ж & 85,0 & 0,393 & 0,440 & 0,401 & 0,93 & 1,11 & 0,50 & 1,68 & 1,66 & 0,59 \\
\hline $\mathrm{K}_{1}$ & 86,4 & 0,388 & 0,434 & 0,402 & 0,93 & 1,13 & 0,52 & 1,61 & 1,63 & 0,65 \\
\hline $\mathrm{K}_{2}$ & 88,6 & 0,383 & 0,431 & 0,394 & 0,97 & 1,20 & 0,72 & 1,53 & 1,55 & 0,95 \\
\hline $\mathrm{OC}_{1}$ & 89,4 & 0,377 & 0,431 & 0,386 & 1,04 & 1,23 & 0,85 & 1,51 & 1,52 & 1,21 \\
\hline $\mathrm{OC}_{2}$ & 90,0 & 0,375 & 0,432 & 0,381 & 1,17 & 1,28 & 0,92 & 1,57 & 1,57 & 1,33 \\
\hline $\mathrm{OC}_{3}$ & 90,8 & 0,377 & 0,420 & 0,378 & 1,15 & 1,24 & 0,92 & 1,56 & 1,55 & 1,44 \\
\hline $\mathrm{T}$ & 91,2 & 0,365 & 0,408 & 0,361 & 1,16 & 1,21 & 1,10 & 1,74 & 1,77 & 1,68 \\
\hline $\mathrm{A}_{1}$ & 93,3 & 0,369 & 0,376 & 0,357 & 1,41 & 1,47 & 1,38 & 1,89 & 1,90 & 1,88 \\
\hline $\mathrm{A}_{2}$ & 94,6 & 0,365 & 0,369 & 0,363 & 1,44 & 1,45 & 1,48 & 1,90 & 1,88 & 1,90 \\
\hline $\mathrm{A}_{3}$ & 95,1 & 0,366 & 0,370 & 0,364 & 1,46 & 1,50 & 1,48 & 1,93 & 1,91 & 1,95 \\
\hline $\mathrm{A}_{4}$ & 95,2 & 0,368 & 0,370 & 0,353 & 1,47 & 1,49 & 1,48 & 1,94 & 1,93 & 1,93 \\
\hline $\mathrm{A}_{5}$ & 95,2 & 0,367 & 0,368 & 0,368 & 1,55 & 1,57 & 1,53 & 1,92 & 1,95 & 1,92 \\
\hline $\mathrm{A}_{6}$ & 95,6 & 0,368 & 0,370 & 0,368 & 1,51 & 1,56 & 1,54 & 1,91 & 1,94 & 1,92 \\
\hline
\end{tabular}

1) СВУ получены при $\mathrm{R}_{\mathrm{ox}}=20$ моль'кГ-1.

2) $\mathrm{CBУ}$ получены при $\mathrm{R}_{\mathrm{ox}}=50$ моль'к $\Gamma^{-1}$. 

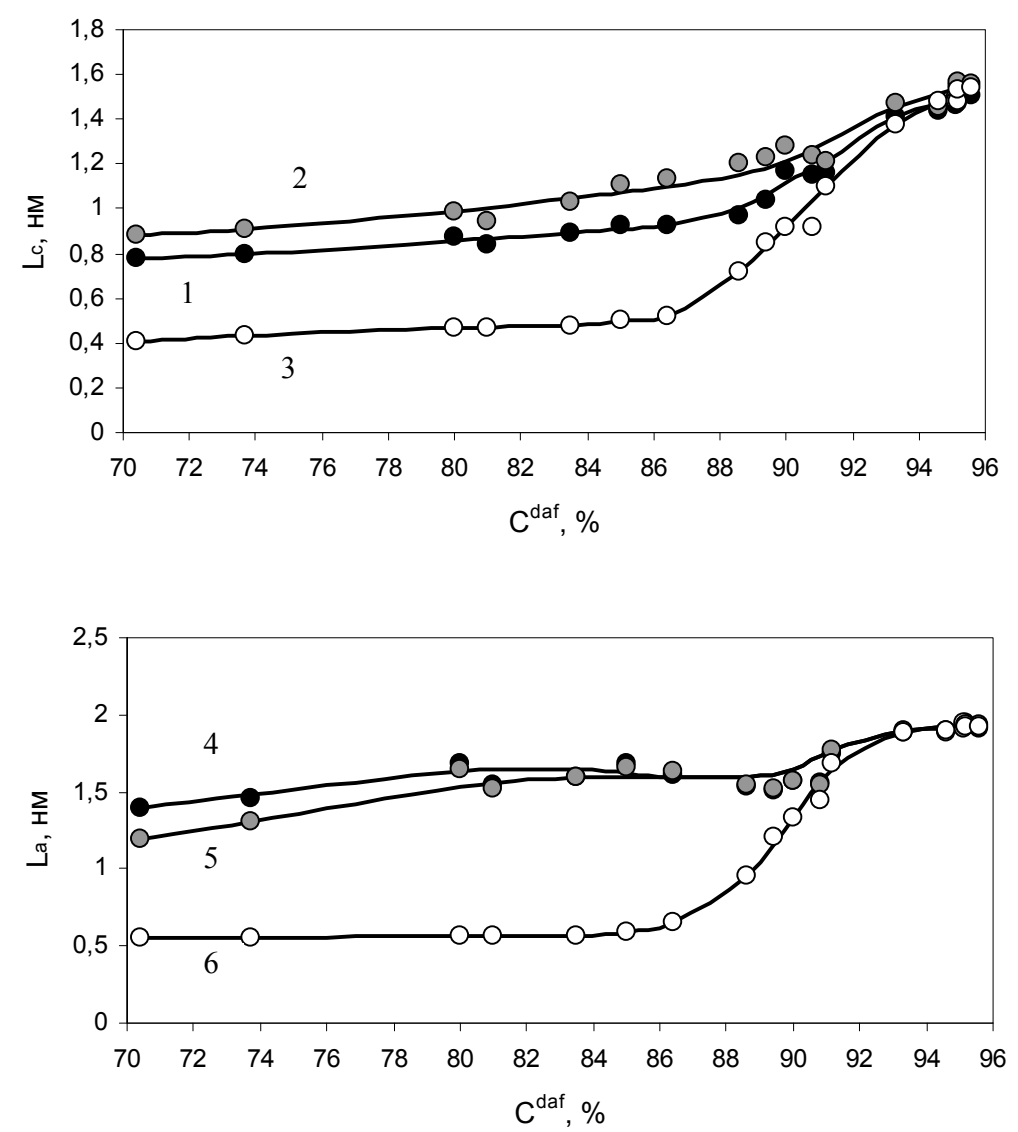

Рис. 4. Зависимость высоты $\mathrm{L}_{c}(1,2,3)$ и среднего диаметра $\mathrm{L}_{\mathrm{a}}(4,5,6)$ «кристаллитов» от $\mathrm{C}^{\mathrm{daf}}$ : 1, 4 - исходный уголь; 2, 5 - СВУ, полученные при $\mathrm{R}_{\text {ох }}=20$ моль'кГ-1; 3, 6 - СВУ, полученные при $\mathrm{R}_{\mathrm{ox}}=50$ моль'кГ-1

сильно для угля в интервале $70<\mathrm{C}^{\mathrm{daf}} \leq 86 \%$; структурные параметры антрацитов практически не изменяются. Объем $\left(\mathrm{V}_{\text {кр }}\right)$ кристалитов $\mathrm{CMC}$, полученных при $\mathrm{R}_{\mathrm{ox}}=20$ моль'кг-1, передается линей 2 на рис. 5. Для $\mathrm{CMC}$ из каменного угля ( $\left.\mathrm{C}^{\mathrm{daf}} \geq 80 \%\right)$ значения $\mathrm{V}_{\text {кр }}$ больше в сравнении с исходными образцами, а для СМС из бурого угля (C $\left.\mathrm{C}^{\mathrm{daf}} 70-75 \%\right)$ - меньше. Линия 3 на рис. 5 отвечает значению $\mathrm{V}_{\text {кр }}$ и для твердых продуктов, полученных при $\mathrm{R}_{\mathrm{ox}}=50$ мольккГ-1, $\mathrm{V}_{\text {кр }}$ существенно меньше, особенно для образцов с $\mathrm{C}^{\mathrm{daf}} \leq 85 \%$.

Таким образом, для большинства углей наблюдается следующая закономерность: с ростом $\mathrm{R}_{\text {ох }}$ объем $\mathrm{V}_{\text {кр }}$ увеличивается (что и ожидалось из модели интеркалирования), а потом уменьшается.

Планарные слои частично оксидеструктируются, что регистрируется как уменьшение площади единичного слоя $\left(\mathrm{S}_{\mathrm{ar}}\right)$ «кристаллита», выраженного соотношением $\mathrm{Rs}=\mathrm{S}_{\mathrm{ar}}(\mathrm{CMK}) /$ $\mathrm{S}_{\mathrm{ar}}$ (уголь). Оно наиболее значимо для угля с $\mathrm{C}^{\mathrm{daf}}<85 \%$, как показано на рис. 5 , в то время как при $\mathrm{C}^{\text {daf }}>90 \%$ оксидеструкции «кристаллитов» почти не происходит.

Таким образом, увеличение значений $\mathrm{d}_{002}, \mathrm{~L}_{c}, \mathrm{~V}_{\text {кр }}$ в $\mathrm{CMC}$ при невысоких $\mathrm{R}_{\text {ох }}$ обусловлено интеркалированием частиц реакционной среды, что также регистрируется по увеличению веса и визуально проявляется как набухание (см. рис. 1).

$$
-106-
$$



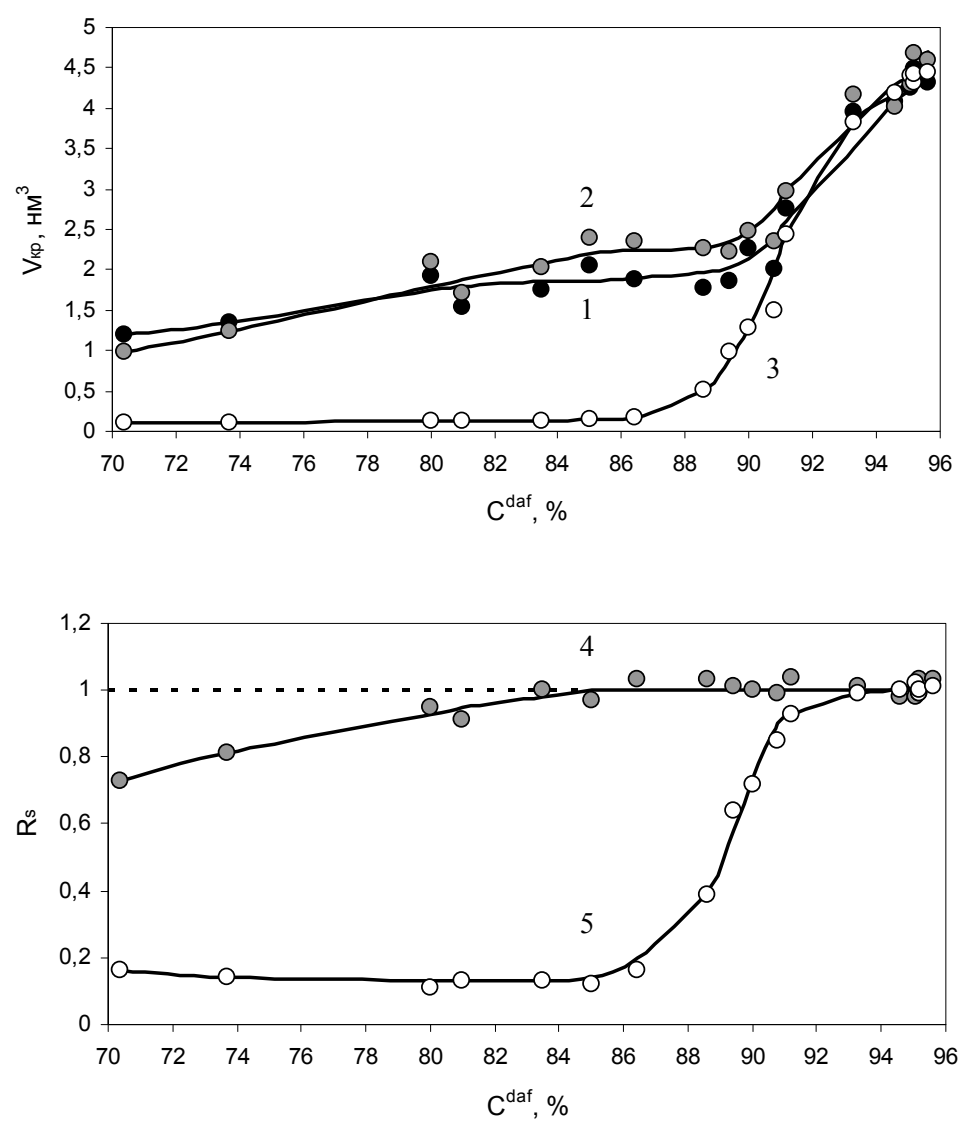

Рис. 5. Зависимости объема «кристаллитов» $\mathrm{V}_{\text {кр }}(1,2,3)$ и соотношения $\mathrm{R}_{\mathrm{s}}(4,5)$ от $\mathrm{C}^{\mathrm{daf}}: 1$ - исходный

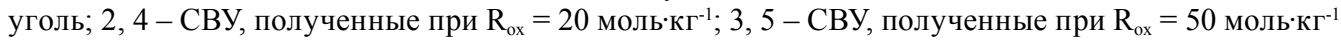

В этом случае расщепление полиареновых планарных фрагментов почти не происходит. В то же время, судя по отсутствию новых рефлексов на дифрактограммах, в СМС нет отдельных двумерно упорядоченных слоев частиц-гостей, включенных в трехмерный угольный каркас. Параллельно интеркалированию развивается оксидеструкция, что становится заметным при $\mathrm{R}_{\text {ох }}>20$ моль'кг $\Gamma^{-1}$, и ведет к разрушению каркаса-хозяина с образованием аморфных оксипродуктов.

При интеркалировании в системе $\mathrm{HNO}_{3}-\mathrm{Ac}_{2} \mathrm{O}$ реализуются химические реакции, которые изменяют молекулярное строение каркаса-хозяина $[13,14,22,23,27,28]$. Их совокупность определена как химическая модификация угля и сопровождается изменениями элементного состава (табл. 2).

Увеличение содержания азота свидетельствует о появлении нитрогрупп и, вероятно, других $\mathrm{N}$-содержащих фрагментов. Если рост величин $\mathrm{N}^{\mathrm{daf}}$ отнести только за счет $\mathrm{NO}_{2}$-групп, то расчетные значения $\mathrm{O}^{\mathrm{daf}}$ составят $13,9\left(\mathrm{~K}_{2}\right) ; 12,7\left(\mathrm{OC}_{2}\right)$ и $12,9 \%\left(\mathrm{OC}_{3}\right)$. Они ниже экспериментальных (см. табл. 2), т.е. нитрование отвечает лишь за некоторую часть $(0,46-0,54)$ общего увеличения $\mathrm{O}^{\mathrm{daf}}$. Остальной кислород вводится в угольный каркас за счет реакций окисления. Исходя из материального баланса по углероду при переходе «уголь $\rightarrow$ СВУ», расчетные значения $\mathrm{C}^{\mathrm{daf}}$ 
Таблица 2. Элементный состав органического вещества исходного угля и СВУ

\begin{tabular}{|c|c|c|c|c|c|c|}
\hline \multirow{2}{*}{ Уголь } & \multirow{2}{*}{ Образец } & \multicolumn{5}{|c|}{ Содержание элементов, \% daf } \\
\hline & & $\mathrm{C}$ & $\mathrm{H}$ & $\mathrm{S}$ & $\mathrm{N}$ & $\mathrm{O}^{\mathrm{d}}$ \\
\hline \multirow{2}{*}{$\mathrm{K}_{2}$} & Уголь & 88,6 & 4,8 & 1,6 & 1,4 & 3,6 \\
\hline & $\mathrm{CBY}^{1)}$ & 62,9 & 4,2 & 1,1 & 5,9 & 25,9 \\
\hline \multirow{2}{*}{$\mathrm{OC}_{2}$} & Уголь & 90,0 & 4,4 & 0,9 & 1,6 & 3,1 \\
\hline & $\mathrm{CBY}^{1)}$ & 66,4 & 4,1 & 0,9 & 5,8 & 22,8 \\
\hline \multirow{2}{*}{$\mathrm{OC}_{3}$} & Уголь & 90,8 & 4,1 & 0,9 & 1,4 & 2,8 \\
\hline & CBУ ${ }^{1)}$ & 66,9 & 4,0 & 0,9 & 5,8 & 22,4 \\
\hline \multirow{2}{*}{ Сп } & Уголь & 82,6 & 9,5 & 0,3 & 0,7 & 6,9 \\
\hline & $\mathrm{CBY}^{2)}$ & 64,4 & 8,2 & 0,2 & 4,5 & 22,7 \\
\hline
\end{tabular}

1) $\mathrm{CBУ} \mathrm{получены} \mathrm{при} \mathrm{R}_{\mathrm{ox}}=50$ моль:к $\Gamma^{-1}, \tau_{\mathrm{ox}}=24$ ч.

2) $\mathrm{CBУ} \mathrm{получены} \mathrm{при} \mathrm{R}_{\mathrm{ox}}=20$ моль'кГ-1, $\tau_{\mathrm{ox}}=24$ ч.

составляют 57,9 $\left(\mathrm{K}_{2}\right) ; 60,4\left(\mathrm{OC}_{2}\right) ; 61,4$ \% $\left(\mathrm{OC}_{3}\right)$. Экспериментальные значения $\mathrm{C}^{\mathrm{daf}}$ выше, что свидетельствует о протекании реакций, связанных с присоединением С-атомов, единственными донорами которых являются молекулы и анионы уксусной кислоты. Таким образом, химическая модификация включает изменения молекулярного строения каркаса-хозяина за счет образования новых функциональных групп.

Судя по данным ИК-спектроскопии (рис. 6), сопоставленным с описанными в литератуpe [29-32], все СВУ содержат ароматические фрагменты: регистрируется поглощение колебаний скелетных $\mathrm{C}=\mathrm{C}-$ связей $\left(1600 \pm 4 \mathrm{~cm}^{-1}\right)$ и валентных $\mathrm{C}_{\mathrm{ar}}-\mathrm{H}\left(3040-3030\right.$ см$\left.^{-1}\right)$ связей. Также регистрируются внеплоскостные деформационные колебания изолированных ароматических Н-атомов в аренах $\left(900 \mathrm{~cm}^{-1}\right)$ и многоядерных нитроаренах $\left(836 \pm 2 \mathrm{~cm}^{-1}\right)$.

Область внеплоскостных колебаний $\mathrm{C}_{\mathrm{ar}}-\mathrm{H}$ связей $\mathrm{CMC}$ значительно отличается от таковой исходного угля, где четко идентифицируются изолированные (900-840 см-1), два, три (840$\left.780 \mathrm{~cm}^{-1}\right)$ и четыре (780-720 $\left.\mathrm{cm}^{-1}\right)$ соседних Н-атома в ароматическом кольце.

Bсе CВУ содержат нитрогруппы: регистрируются асимметричные $\left(1540 \mathrm{~cm}^{-1}\right)$ и симметричные $\left(1350 \mathrm{~cm}^{-1}\right)$ валентные и деформационные $\left(750 \mathrm{~cm}^{-1}\right)$ колебания. Их содержание приблизительно одинаково для угля с $\mathrm{C}^{\mathrm{daf}} \leq 90$ \% и дальше резко снижается при переходе к антрацитам (рис. 7). В структуре низкометаморфизованных СВУ выявлены алифатические нитрогруппы $\left(1554 \pm 2 \mathrm{~cm}^{-1}, 1373 \pm 2 \mathrm{~cm}^{-1}\right)$, ковалентные нитраты $\left(1640,1250 \mathrm{~cm}^{-1}\right)$ и, вероятно, нитрозогруппы $\left(1506 \pm 2 \mathrm{~cm}^{-1}\right)$.

В условиях модификации образуются карбонильные группы, которые идентифицируются по наличию сильной полосы при $(1720 \pm 5) \mathrm{cm}^{-1}$. В СВУ они представлены главным образом карбоксильными группами: щелочная обработка приводит к исчезновению полосы при $(1720 \pm 5) \mathrm{cm}^{-1}$ и появлению двух полос при 1570 и $1400 \mathrm{~cm}^{-1}$, что характерно для перехода карбоксильных групп в карбоксилаты калия. После удаления щелочи спектральная картина восстанавливается.

Некоторые $\mathrm{COOH-группы} \mathrm{находятся} \mathrm{в} \mathrm{1,2-положении} \mathrm{и} \mathrm{в} \mathrm{условиях} \mathrm{мягкого} \mathrm{нагревания}$ $\left(180{ }^{\circ} \mathrm{C}, 1\right.$ ч, Ar) образуют ангидриды, которые регистрируются как появление полос при 


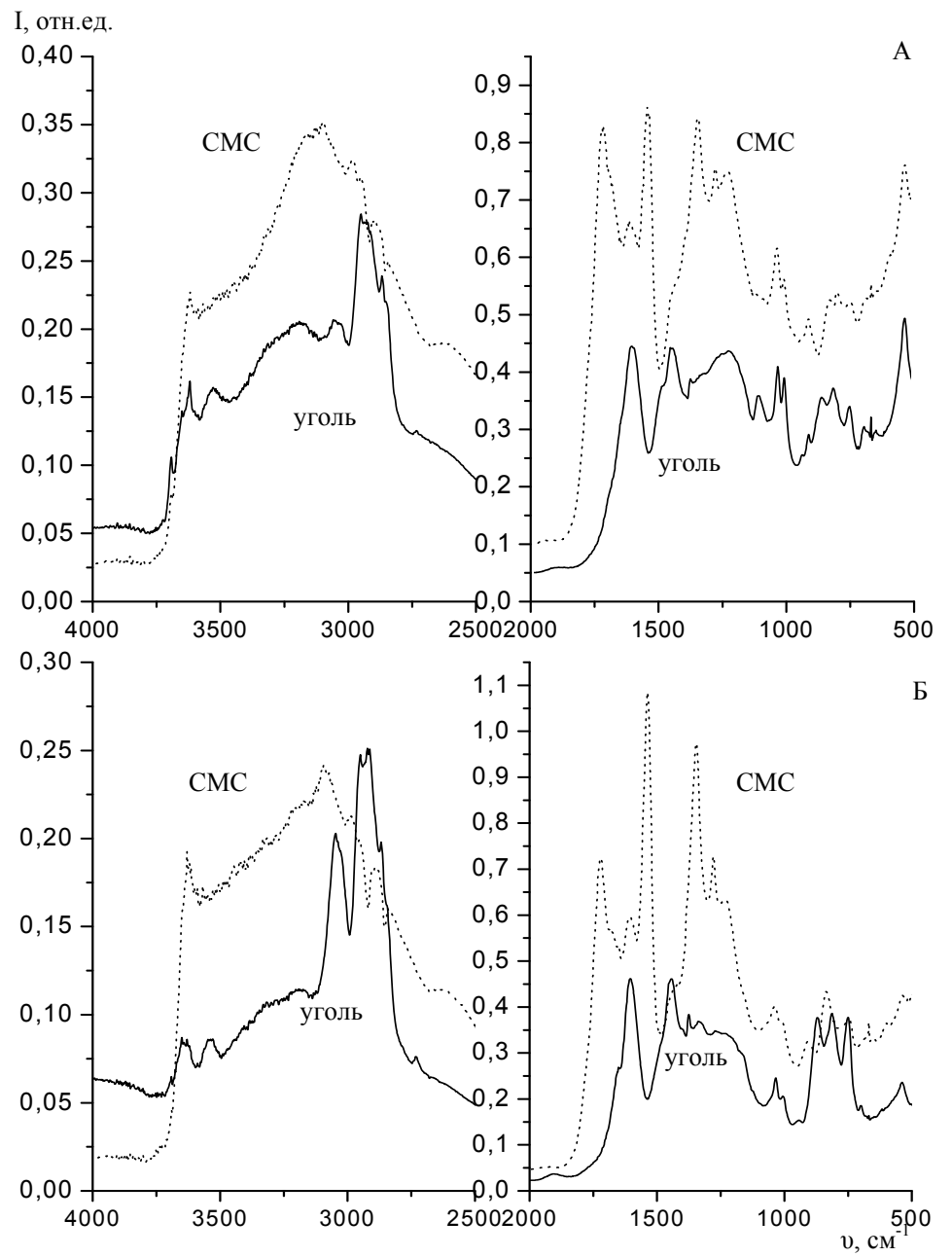

Рис. 6. ИК-спектры исходного и структурно модифицированного углей: А - уголь марки Г $\left(\mathrm{C}^{\mathrm{daf}}=81,0 \%\right)$; Б - уголь марки $\mathrm{K}\left(\mathrm{C}^{\mathrm{daf}}=88,6 \%\right)$

$(1845 \pm 5) \mathrm{cm}^{-1}$ и $(1775 \pm 5) \mathrm{cm}^{-1}$. В СВУ идентифицированы хиноидные циклы (полоса при $\left.(1653 \pm 4) \mathrm{cm}^{-1}\right)$ и фенольные группы (поглощение при 3500-3400 см${ }^{-1}$ и $\left.(1340 \pm 4) \mathrm{cm}^{-1}\right)$. При переходе «уголь $\rightarrow \mathrm{CBУ»} \mathrm{также} \mathrm{возрастает} \mathrm{интенсивность} \mathrm{поглощения} \mathrm{валентных} \mathrm{колеба-}$ ний С-О-связей фенолов. В области С-О связей эфиров (1300-1200 см-1) наблюдаются две полосы при 1230 и $1270 \mathrm{~cm}^{-1}$. Первая относится к С-О-связям сложных эфиров и исчезает после щелочной обработки вследствие гетеролиза и образования фенолятов. Полоса при $1270 \mathrm{~cm}^{-1}$ не реагирует на щелочную обработку СМС, потому она отнесена к С-O-связям простых эфиров.

Количество алифатических фрагментов в СВУ мало: наблюдается небольшое поглощение валентных (3200-2800 см$\left.{ }^{-1}\right)$ и деформационных (1440 $\left.\pm 5 \mathrm{~cm}^{-1}\right)$ колебаний $\mathrm{CH}_{3}-$ и $-\mathrm{CH}_{2}$-групп. Их количество меньше, чем в исходном угле, в ИК-спектрах которых регистрируются интенсивные полосы поглощения $\mathrm{CH}_{3}$-групп (2955 \pm 7 и $\left.2870 \pm 2 \mathrm{~cm}^{-1}\right)$ и $-\mathrm{CH}_{2}$ - групп $\left(2925 \pm 5\right.$ и $\left.2865 \pm 5 \mathrm{~cm}^{-1}\right)$ и также их деформационные колебания $\left(1440 \pm 5 \mathrm{~cm}^{-1}\right)$. Таким образом, количество алифатиче- 

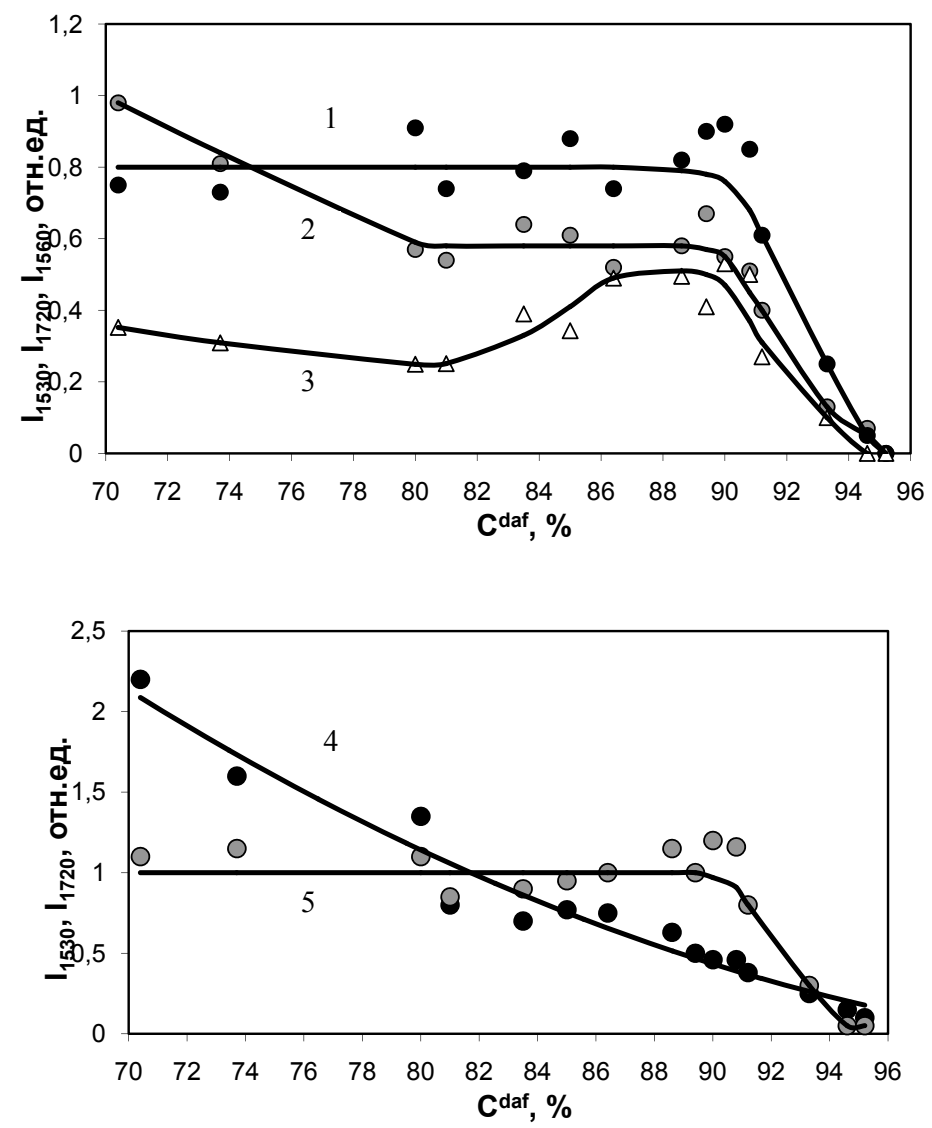

Рис. 7. Зависимости интенсивностей $\mathrm{I}_{1530}(1,5), \mathrm{I}_{1720}(2,4)$ и $\mathrm{I}_{1560}(3)$ для CВУ, полученных из угля разной СМ от $\mathrm{C}^{\text {daf: }}: 1,2,3-\mathrm{R}_{\mathrm{ox}}=20$ моль ${ }^{-1} \Gamma^{-1} ; 4,5-\mathrm{R}_{\mathrm{ox}}=50$ моль к $^{-1}$

ских связей между нитроаренами СМС невелико, а основное количество межмолекулярных ковалентных связей осуществляется за счет сложноэфирных груп.

В формировании трехмерного каркаса СВУ принимают участие межмолекулярные водородные связи: колебания ОН-групп СВУ поглощают в широкой области (3400- $\left.3200 \mathrm{~cm}^{-1}\right)$, как это характерно для водородных связей в полимерах. Нитрогруппы образуют водородные связи типа $\operatorname{Ar}-\mathrm{N}(\mathrm{O})=\mathrm{O} \ldots \mathrm{HO}-\mathrm{R}$, как в твердых п-нитрофенолах. Это является причиной выхода $\mathrm{NO}_{2}$-группы из площади нитроарена СМС и более высоких значений волновых чисел (1540 и $\left.1350 \mathrm{~cm}^{-1}\right)$ по сравнению с валентными колебаниями (1530 и $\left.1330 \mathrm{~cm}^{-1}\right) \mathrm{NO}_{2}$-групп на поверхности углеродных материалов.

Таким образом, основными каркасообразующими элементами СВУ считаются нитроароматические фрагменты, размеры которых увеличиваются с ростом СМ. Фрагменты агрегированы в «кристаллиты» с приблизительно параллельной упаковкой слоев и связаны между собой эфирными и алифатическиими мостиками, а также межмолекулярными нековалентными связями. Содержание ароматических $\mathrm{NO}_{2}$-групп приблизительно одинаково для СВУ из угля в широком диапазоне CM (C $\mathrm{C}^{\mathrm{daf}} 70-90 \%$ ) и резко снижается у СВУ из антрацитов. Алифатические нитрогруппы идентифицированы только в низкометаморфизованных углях ( $\left.\mathrm{C}^{\mathrm{daf}} \leq 80 \%\right)$. Bce 
СВУ содержат кислородные функциональные группы, состав которых варьируется с изменением СМ. Содержание СООН-групп снижается с ростом значений $\mathrm{C}^{\mathrm{daf}}$. Хиноидные циклы и эфирные группы присутствуют во всех образцах. Независимо от СМ часть нативных алифатических фрагментов разных типов сохраняется при модификации угля в системе $\mathrm{HNO}_{3}-\mathrm{Ac}_{2} \mathrm{O}$ и принимает участие в формировании пространственного каркаса СВУ. Метильные группы, скорее всего, отсутствуют, поскольку легко окисляются до СООН-групп.

Модифицированные антрациты отличаются от других веществ. Глубина модификации и изменения структурных параметров незначительны. Ароматические нитрогруппы антрацитовых СВУ проявляются при $(1530 \pm 2) \mathrm{cm}^{-1}$ и $(1385 \pm 2) \mathrm{cm}^{-1}$, что не похоже на $\mathrm{C}_{\mathrm{ar}}-\mathrm{NO}_{2}$ фрагменты других CВУ: асимметричные колебания $\mathrm{NO}_{2}$-групп наблюдаются в той же области, а полоса симметричных валентных колебаний сдвинута (1340 $\pm 2 \mathrm{~cm}^{-1}$ против $\left.1385 \pm 2 \mathrm{~cm}^{-1}\right)$ в область поглощения органических нитратов (1410-1350 см-1). Антрацитовые СВУ также содержат карбонильные группы (поглощение при $1715 \mathrm{~cm}^{-1}$ ), которые относятся к ароматическим СООНгрупам и сопряженным кетонам типа $\mathrm{Ar}-\mathrm{C}(\mathrm{O})$-Ar. Хиноидные группы проявляются полосой при $(1649 \pm 2)$ см$^{-1}$, что отвечает поглощению $\mathrm{C}=\mathrm{O}$ связей в многоядерных нитроаренах с хиноидниыми группами в разных кольцах. Кислород в антрацитовых СВУ представлен главным образом эфирными группами, поскольку интенсивность поглощения в области 1200-1100 см-1 выше, чем при 1750-1500 см-1.

Результаты исследований позволяют предложить реакционные схемы превращений структурных фрагментов угля при модификации в системе $\mathrm{HNO}_{3}-\mathrm{Ac}_{2} \mathrm{O}$ [22, 27, 28, 33, 34].

Электрофильное замещение в угольных аренах происходит аналогично нитрованию индивидуальных ароматических соединений:

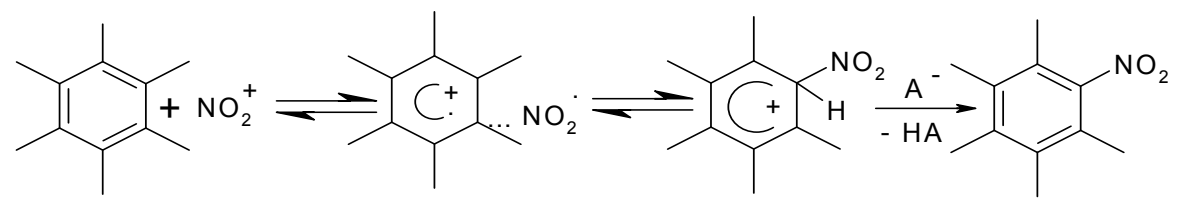

Взаимодействие идет через медленную стадию образования ион-радикальной пары, далее аренониевого иона с последующим отрывом протона основанием Бренстеда (AcO-). Результатом является образование нитроарена и молекулы АсОН, которая удерживается в полости трехмерного угольного каркаса. Присутствие в СМС угольных аренониевих ионов экспериментально не зафиксировано, вероятно, вследствие их короткого времени жизни, обусловленного сильной нуклеофильностью ацетат-аниона.

Генерация угольных катион-радикалов проходит за счет распада ион-радикальной пары:

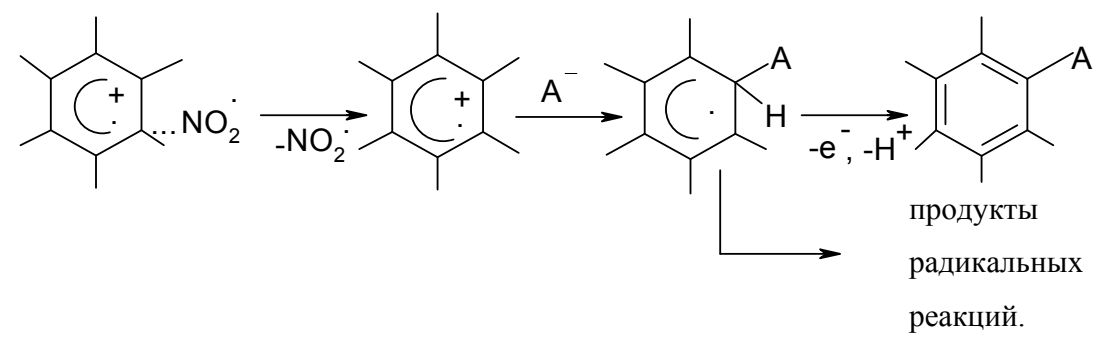


В пользу этого свидетельствует интенсивное выделение газообразного $\mathrm{NO}_{2}$, который фактически удаляет электроны угля во внешнюю среду. Накопление угольных радикалов при модификации в системе $\mathrm{HNO}_{3}-\mathrm{Ac}_{2} \mathrm{O}$ не зарегистрировано. Они активны и быстро реагируют дальше с образованием более стабильных продуктов. Тут осуществляется компенсация положительного заряда, например в реакциях ацетоксилирования, а также вероятны радикальные реакции.

Частичная оксидеструкция аренов идет через последовательное образование фенольных, хиноидных групп, а также фрагментов орто-дикарбоновых кислот, образующих ангидриды при термической дегидратации:<smiles>Cc1c(C)c(C(=O)O)c(C(=O)O)c(C(=O)O)c1C</smiles>

O разрыве ароматических колец также свидетельствует снижение средней площади $\left(\mathrm{S}_{\mathrm{ar}}\right)$ ароматических слоев, которые составляют «кристаллиты» СВУ. Степень низкотемпературного выгорания «кристаллитов» велика для углей от бурого до коксового, но резко снижается практически до нуля при $\mathrm{C}^{\mathrm{daf}} \rightarrow 90 \%$ (рис. 5). Уменьшение глубины оксидеструкции при переходе от угля ОC ( $\left.\mathrm{C}^{\mathrm{daf}}=90,0 \%\right)$ к антрацитам также сопровождается снижением прироста массы $\Delta \mathrm{m}$, степени нитрования и окисления. Модификация антрацита ( $\mathrm{C}^{\mathrm{daf}}$ 95,2 \%) уже слабо реорганизует его структуру, не разрушает «кристаллиты», не расщепляет арены, но приводит к появлению

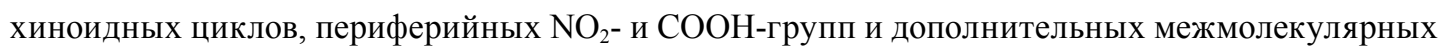
связей типа $\mathrm{Ar}-\mathrm{O}-\mathrm{Ar}_{1}$.

Окисление и нитрование алифатических фрагментов отображается схемами:

$$
\mathrm{Ar}-\mathrm{CH}_{3} \rightarrow \mathrm{Ar}-\mathrm{C}(\mathrm{O})-\mathrm{H} \rightarrow \mathrm{Ar}-\mathrm{COOH}, \quad \mathrm{Ar}-\mathrm{CH}_{3} \rightarrow \mathrm{Ar}-\mathrm{CH}_{2}-\mathrm{NO}_{2}
$$

В соответствии с ними снижается интенсивность поглощения колебаний метильных групп $\left(2955 \pm 7\right.$ и $\left.2870 \pm 2 \mathrm{~cm}^{-1}\right)$, увеличивается концентрация карбонильных функций $\left(1720 \pm 5 \mathrm{~cm}^{-1}\right)$ и проявляются полосы поглощения алифатических $\mathrm{NO}_{2}$-групп $\left(1554 \pm 2\right.$ и $\left.1373 \pm 2 \mathrm{~cm}^{-1}\right)$ и $-\mathrm{CH}_{2}$ групп в фрагменте $-\mathrm{CH}_{2}-\mathrm{NO}_{2}\left(1344 \mathrm{~cm}^{-1}\right)$.

Окисление метиленовых фрагментов приводит к образованию кетонов и эфиров:

$$
\mathrm{Ar}-\mathrm{CH}_{2}-\mathrm{Ar}_{1} \rightarrow \mathrm{Ar}-\mathrm{C}(\mathrm{O})-\mathrm{Ar}_{1} ; \quad \mathrm{Ar}-\mathrm{C}(\mathrm{O})-\mathrm{O}-\mathrm{Ar}_{1} ; \mathrm{Ar}-\mathrm{O}-\mathrm{Ar}_{1}
$$

или оксидеструкции метиленовых мостиков между угольными макромолекулами:

$$
\mathrm{Ar}-\mathrm{CH}_{2}-\mathrm{Ar}_{1} \rightarrow \mathrm{Ar}-\mathrm{OH}+\mathrm{Ar}_{1}-\mathrm{COOH}
$$

которое становится возможным при условии пространственной подвижности фрагментов $\mathrm{Ar}$ и $\mathrm{Ar}_{1}$.

Схемы отражают изменение типа ковалентных связей между угольными аренами, а также разрыв внутрикаркасных связей при переходе «уголь $\rightarrow \mathrm{CBУ»} \mathrm{и} \mathrm{подтверждаются} \mathrm{снижением}$ интенсивности поглощения колебаний $-\mathrm{CH}_{2}$-фрагментов $\left(2925 \pm 5,2875 \pm 2,1440 \pm 2 \mathrm{~cm}^{-1}\right)$ па- 
раллельно с ростом интенсивности поглощения сопряженных кетонов и эфиров. Оксидеструкция метиленовых мостиковых связей или их замена на сложноэфирные мостики - причина повышения выходов продуктов щелочной фрагментации СВУ, что возможно только при наличии достаточно большого количества межмолекулярных связей, которые легко расщепляются щелочами при комнатных температурах.

Описанный набор реакций и обусловливает переход «уголь $\rightarrow$ СВУ», а образованные структурные элементы и функциональные группы формируют новый пространственный каркас с другим набором ковалентных связей и другим уровнем нековалентных межмолекулярных взаимодействий. Большинство СВУ по структуре и набору свойств резко отличаются от своих предшественников - ископаемых углей. Рассматривая их как новые, малоизученные угольные вещества, считаем целесообразным более подробно изучить термолиз самого СВУ как основу для исследования термолиза СВУ в присутствии щелочи, а именно в процессе получения АУ.

\section{Термолиз соединений внедрения углей}

Все СВУ более термолабильны по сравнению с исходным углем [35]. Основная потеря массы осуществляется в области низких температур (рис. 8), что связано с разложением образованных вследствие модификации новых структурных центров. Это проявляется в виде дополнительных максимумов 2 и 3 (рис. 9) скоростей образования летучих продуктов ( $)$ ). Пик 1 , который обычно относят к термодесорбции воды, наблюдается для СВУ и угля. Широкий пик 4 обусловлен развитием характерных для полукоксования процессов термодеструкции и формирования нового макромолекулярного каркаса.

Термическое разложение новых центров практически завершается до температуры $400^{\circ} \mathrm{C}$, что обусловливает более высокий выход летучих продуктов термолиза СВУ по сравнению с исходным углем. Суммарный выход летучих веществ при нагревании до $400{ }^{\circ} \mathrm{C}$ принят в качестве условного параметра термолабильности и обозначен нами в этой работе как $\mathrm{V}_{400}^{\mathrm{a}}$. Исходя из зависимостей значений $\mathrm{V}^{\mathrm{a}}{ }_{400}$ от $\mathrm{C}^{\mathrm{daf}}$ (рис. 10), выход летучих продуктов термолиза исходного угля резко уменьшается от бурого угля к коксовому (от 46 до 5-6 \%) и далее изменяется мало -

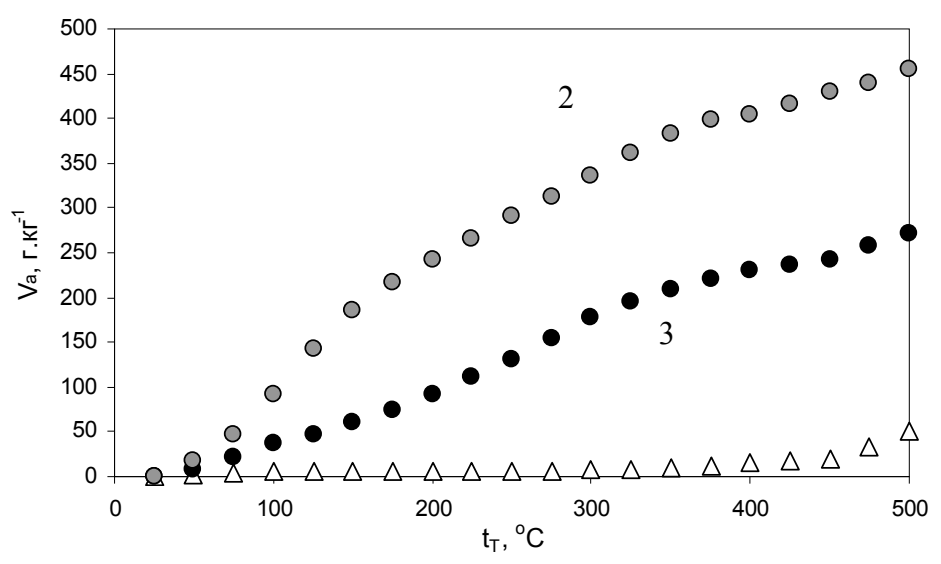

Рис. 8. Температурные зависимости выходов летучих веществ $\mathrm{V}^{\mathrm{a}}$ при нагревании угля $\mathrm{K}_{2}(1)$, СВУ (2) и продукта гидролиза СВУ (3); CВУ получены при $\mathrm{R}_{\mathrm{ox}}=20$ моль'к $\Gamma^{-1}$ 


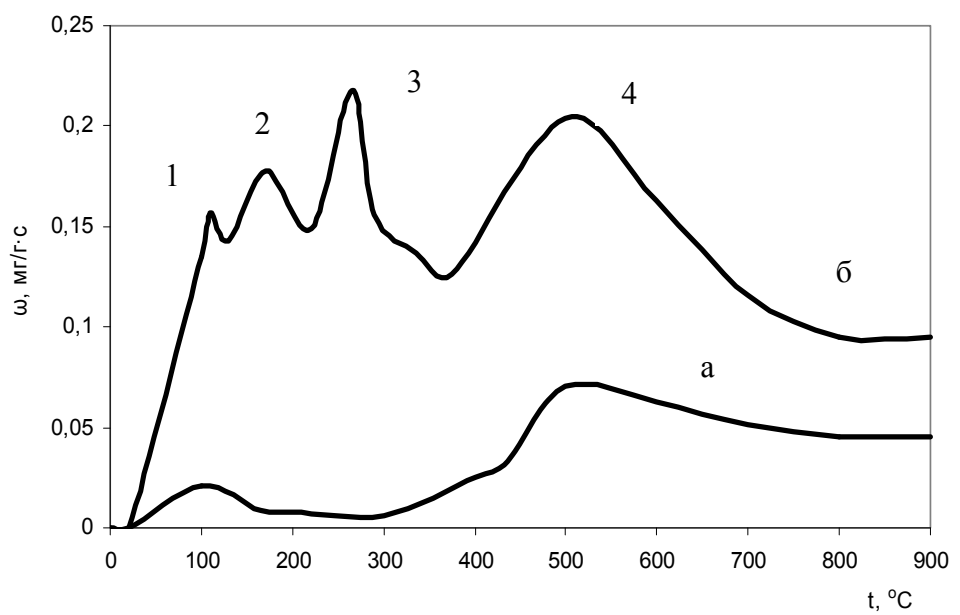

Рис. 9. Температурные зависимости скоростей образования летучих веществ ( $)$ при нагревании исходного (а) и структурно-модифицированного (б) угля марки ОС $\left(\mathrm{C}^{\mathrm{daf}}=90,0 \%\right)$

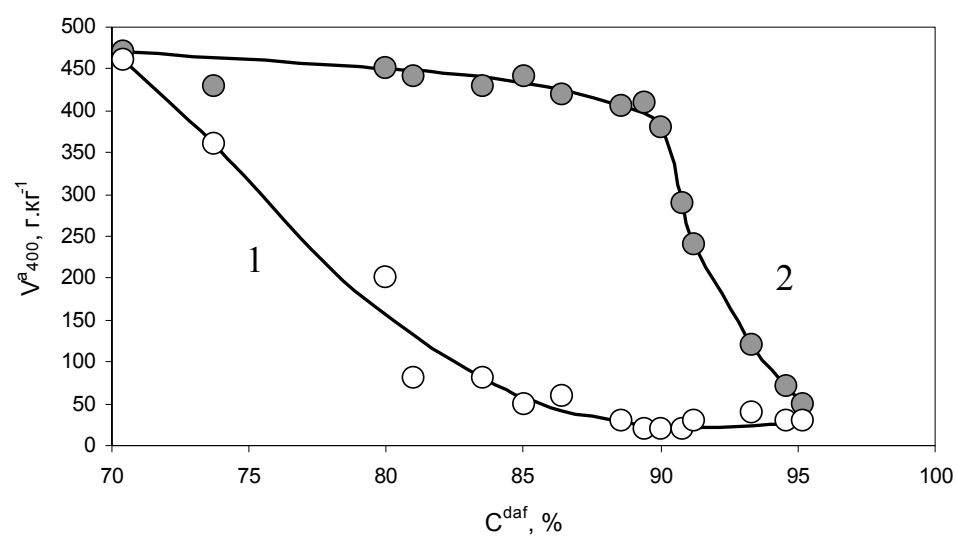

Рис. 10. Зависимость выхода летучих продуктов $\mathrm{V}_{400}^{\mathrm{a}}$ от $\mathrm{C}^{\mathrm{daf}}$ при нагревании исходного угля (1) и CВУ (2), полученных при $\mathrm{R}_{\mathrm{ox}}=20$ моль·к $\Gamma^{-1}$

в пределах 0,7-5 \%. При нагревании СВУ (рис. 10) наблюдается другая картина: термолабильность достаточно велика $\left(\mathrm{V}_{400}^{\mathrm{a}}=30-46 \%\right.$ для $\mathrm{CBУ}$ из угля с $\mathrm{C}^{\mathrm{daf}}$ от 70,4 до 91,2 \%, а при переходе к антрацитам значения $\mathrm{V}_{400}^{\mathrm{a}}$ резко падает. На рис. 11 видно, что наиболее значительный эффект дает модификация угля средней $\mathrm{CM}\left(\mathrm{C}^{\mathrm{daf}}=89-91 \%\right)$ : их термолабильность в 10-36 раз выше по сравнению с исходными образцами.

Положение пиков 1-4 на рис. 9 и максимальные скорости разложения $\omega_{\mathrm{n}}$ структурных центров, отвечающих за эти пики, зависят от СМ угля. В целом, значения $\omega_{n}$ уменьшаются с увеличением $\mathrm{C}^{\mathrm{daf}}$, как и общий выход летучих продуктов, но значения параметра $\omega_{2}$ снижаются с метаморфизмом быстрее, чем $\omega_{3}$. Температуры ( $\mathrm{T}_{\mathrm{n}}$, где $\mathrm{n}-$ номер пика) максимальных скоростей разложения растут (рис. 12) с метаморфизмом. Параметры $\mathrm{T}_{1}$ и $\mathrm{T}_{2}$ слабо изменяются с ростом $\mathrm{C}^{\mathrm{daf}}$, а $\mathrm{T}_{3}$ существенно зависит от СМ. Причем в диапазоне углей с $\mathrm{C}^{\mathrm{daf}}$ от 70,4 до 90,0\% 


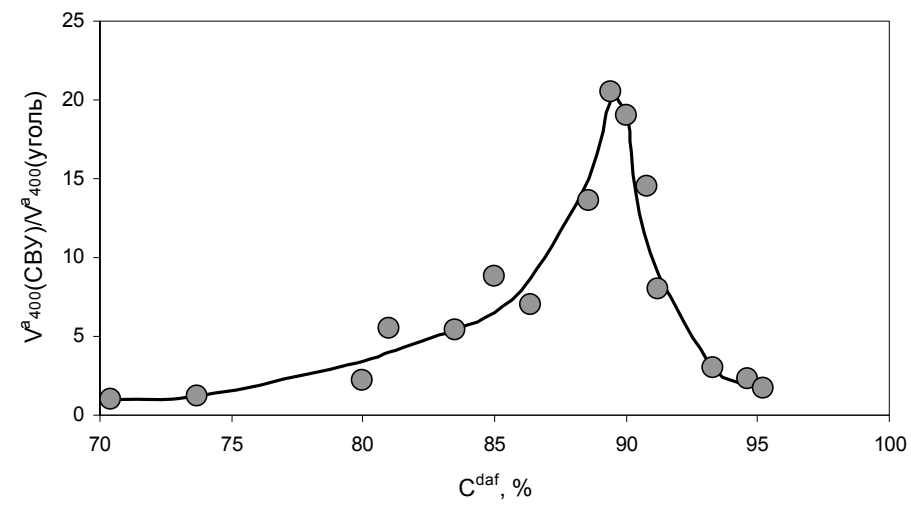

Рис. 11. Соотношения выходов летучих продуктов СВУ и угля как функция $\mathrm{C}^{\mathrm{daf}}$

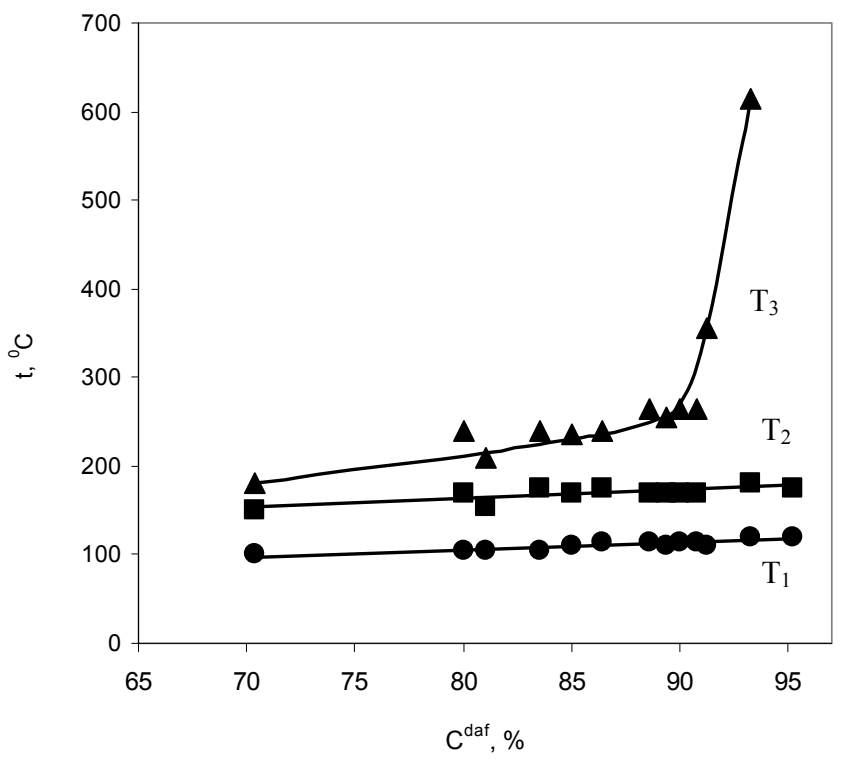

Рис. 12. Температуры максимумов скоростей образования летучих веществ при нагревании СВУ из углей разной степени метаморфизма

значения $\mathrm{T}_{3}$ увеличиваются умеренно, а далее резко растут к антрацитам (Cdaf 95,2 \%). Можно сделать вывод, что структура исходного угля в значительной степени определяет термолабильность новых центров, введенных при модификации.

Термолиз СВУ приводит к существенной реорганизации их структуры (рис. 13). С ростом температуры в ИК-спектрах СВУ появляются полосы валентных колебаний С=О-групп ангидридов $\left(1843 \pm 2\right.$ и $\left.1776 \pm 2 \mathrm{~cm}^{-1}\right)$. Интенсивность поглощения карбонильных функций при $(1720 \pm 5) \mathrm{cm}^{-1}$, что отвечает пику 2 на рис. 9, снижается особенно сильно при нагревании от 175 до $320{ }^{\circ} \mathrm{C}$, но полностью не пропадает вледствие сохранения части карбоксильных групп или их перехода в лактонные структуры. Интенсивные полосы валентных колебаний (1540 \pm 5 и $\left.1350 \pm 5 \mathrm{~cm}^{-1}\right)$ нитрогрупп почти не изменяются при нагревании СВУ до $175{ }^{\circ} \mathrm{C}$. При дальней- 


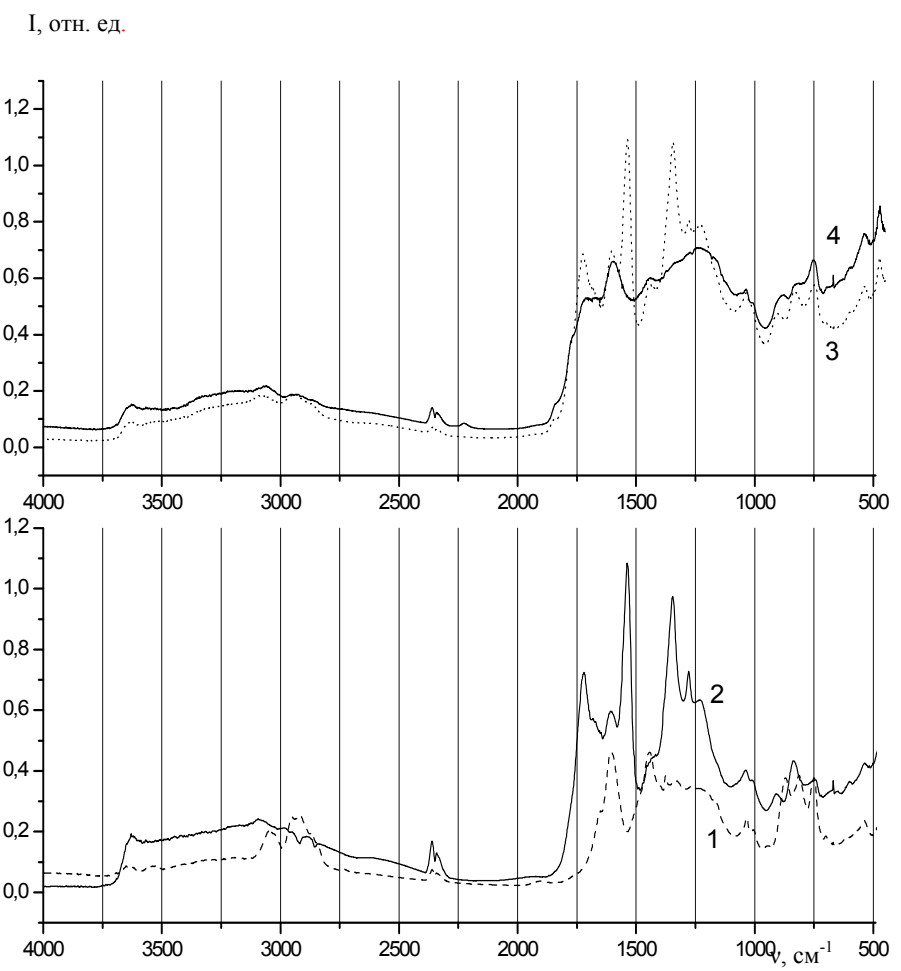

Рис. 13. ИК-спектры угля $\mathrm{K}_{2}(1), \mathrm{CBУ}-K_{2}$ (2) и продуктов термолиза СВУ-К 2 при $175^{\circ} \mathrm{C}(3)$ и $320^{\circ} \mathrm{C}(4)$

шем нагревании (до $320^{\circ} \mathrm{C}$ ) нитрогруппы полностью разлагаются, параллельно образуются нитрильные группы, судя по появлению и увеличению интенсивности полосы колебаний $\mathrm{C} \equiv \mathrm{N}$ связей при $(2226 \pm 2)$ см $^{-1}$. Полосы скелетных колебаний $\mathrm{C}=\mathrm{C}$-связей СВУ смещаются в область более низких частот: с 1612 до 1586 cм$^{-1}$ (уголь Д) и с 1608 до 1598 см-1 (уголь К), что может быть следствием появления в цепи $\pi$-сопряжения гетероциклических азотсодержащих фрагментов.

Термолиз вызывает изменения области колебаний $\mathrm{C}_{\mathrm{ar}}-\mathrm{H}-$ связей (вследствие термодеструкции электроноакцепторных заместителей: $\left.-\mathrm{NO}_{2},-\mathrm{COOH}\right)$, а также области поглощения эфирных и фенольных групп (1300-1050 см-1). Вероятно, ОН-группы принимают участие в термоинициированных реакциях, например в образовании лактонных групп в процессе конденсации с карбоксильными функциями или эфирных групп: $2 \mathrm{Ar}-\mathrm{OH} \rightarrow \mathrm{Ar}-\mathrm{O}-\mathrm{Ar}+\mathrm{H}_{2} \mathrm{O}$. В целом, интенсивность поглощения эфирных групп повышается с ростом температуры нагревания. Алифатические фрагменты СМС существенно не изменяются до температур $300-320{ }^{\circ} \mathrm{C}$ и сохраняются как мостиковые - $\mathrm{CH}_{2}$-связи между ароматичическими структурными фрагментами. Другими словами, образование ангидридных и эфирных групп при мягком нагревании (до $\left.200{ }^{\circ} \mathrm{C}\right)$, как и полное разложение $\mathrm{NO}_{2}$-групп при более высоких $\left(\leq 320^{\circ} \mathrm{C}\right)$ температурах, можно считать общим явлением для всех СВУ.

С ростом температуры изменяется качественный состав газообразных продуктов термолиза, установленный ИК-спектроскопией (отнесения выполнены по данным [36]). Первым $\left(\geq 500{ }^{\circ} \mathrm{C}\right.$ ) продуктом регистрируется вода (полосы при 3700, 3660 и $1600 \mathrm{~cm}^{-1}$ с тонкой вращательной структурой в областях 3800-3400 и 1800-1600 см-1). Ее выделение регистрируется во 
всем диапазоне температур $\left(\leq 400{ }^{\circ} \mathrm{C}\right)$, но наиболее интенсивно при $80-110{ }^{\circ} \mathrm{C}$. Выше $100{ }^{\circ} \mathrm{C}$ заметно выделение $\mathrm{CO}_{2}$ (полосы при $2350 \pm 10$ и $1340 \pm 2 \mathrm{~cm}^{-1}$ ). С повышением температуры количество $\mathrm{CO}_{2}$ в газе увеличивается; выделение $\mathrm{CO}_{2}$ наиболее интенсивно в области $200-300{ }^{\circ} \mathrm{C}$. Выше $250^{\circ} \mathrm{C}$ заметны реакции с образованием оксида углерода (полоса поглощения колебаний СО при $\left.2143 \pm 4 \mathrm{~cm}^{-1}\right)$.

Оксиды азота зафиксированы в газоподобных продуктах при температурах выше $200{ }^{\circ} \mathrm{C}$ по появлению в ИК-спектрах полос поглощения при 1620, 1320 и $750\left(\mathrm{NO}_{2}\right), 1900-1880$ (NO), 2220 и $1290 \mathrm{~cm}^{-1}\left(\mathrm{~N}_{2} \mathrm{O}\right)$.

Независимо от СМ выделяются (см. рис. 9) три области термолиза СВУ, в каждой из которых доминирует собственный (отличный от других областей) набор термоинициированных реакций, отвечающих за появление пиков на температурных зависимостях выделения летучих продуктов.

Область 1 ( $\left.\leq 130{ }^{\circ} \mathrm{C}\right)$ обусловлена удалением повторно адсорбированной влаги, которая удерживается пространственным каркасом СВУ. Процесс сопровождается эндоэффектами, прочность удерживания $\mathrm{H}_{2} \mathrm{O}$ увеличивается с метаморфизмом, что обусловливает сдвиг максимума скорости термодесорбции в сторону больших температур (рис. 12).

Область 2 (130-200 $\left.{ }^{\circ} \mathrm{C}\right)$ характерна только для СВУ и связана с термодеструкцией структурных центров, образованных в условиях модификации угля эквимолярной смесью $\mathrm{HNO}_{3}-$ $\mathrm{Ac}_{2} \mathrm{O}$.

Здесь идентифицированы несколько типов термоинициированных реакций.

1. Ангидридизащия карбоксильных групп:

$$
\mathrm{R}-\mathrm{COOH}+\mathrm{R}_{1}-\mathrm{COOH} \rightarrow \mathrm{R}-\mathrm{C}(\mathrm{O})-\mathrm{O}-\mathrm{C}(\mathrm{O})-\mathrm{R}_{1}+\mathrm{H}_{2} \mathrm{O} .
$$

В СМС появляются ангидридные группы (1770-1780 и 1840-1850 см-1); в летучих продуктах идентифицирована $\mathrm{H}_{2} \mathrm{O}$. Поэтому мы считаем, что образуются как циклические, так и межмолекулярные ангидриды, но однозначно различить их в ИК-спектрах трудно.

2. Образование эфиров за счет реакицй поликонденсации:

$$
\mathrm{R}-\mathrm{OH}+\mathrm{R}_{1}-\mathrm{OH} \rightarrow \mathrm{R}-\mathrm{O}-\mathrm{R}_{1}+\mathrm{H}_{2} \mathrm{O}(\mathrm{R}=\mathrm{Ar}-, \mathrm{Ar}-\mathrm{C}(\mathrm{O})-)
$$

\section{3. Декарбоксилирование:}

$$
\mathrm{R}-\mathrm{COOH} \rightarrow \mathrm{R}-\mathrm{H}+\mathrm{CO}_{2} ; \mathrm{R}-\mathrm{C}(\mathrm{O})-\mathrm{O}-\mathrm{R}_{1} \rightarrow \mathrm{R}-\mathrm{R}_{1}+\mathrm{CO}_{2} .
$$

Концентрация карбоксильных групп снижается в 1,5 раза; интенсивность поглощения валентных колебаний $\mathrm{C}=\mathrm{O}$-связей $\left(1720 \pm 5 \mathrm{~cm}^{-1}\right)$ и $\mathrm{C}-\mathrm{O}-$ связей $\left(1260-1300 \mathrm{~cm}^{-1}\right)$ сложных эфиров и фенолов изменяется. В летучих продуктах термолиза регистрируется диоксид углерода $\left(2349 \mathrm{~cm}^{-1}\right)$.

Область 3 (>200 $\left.{ }^{\circ} \mathrm{C}\right)$ термолиза СМС обусловлена распадом нитрогрупп. В образцах $\mathrm{CMC}$, прогретых до $350{ }^{\circ} \mathrm{C}, \mathrm{NO}_{2}$-группы отсутствуют, а в летучих продуктах появляются оксиды азота. Количество азотсодержащих продуктов невелико, азот нитрогрупп переходит в газоподобные оксиды частично, в термолизованных СМС присутствуют другие N-содержащие группы, в частности нитрильные (полоса $\mathrm{C} \equiv \mathrm{N}$-связей при $2226 \pm 2 \mathrm{~cm}^{-1}$ ) и, вероятно, гетероциклы. Нужно отметить, что и при температурах выше $300{ }^{\circ} \mathrm{C}$ происходят процессы, связанные с выделением 


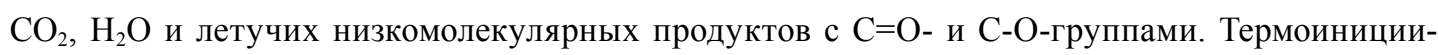
рованные реакции в области 3 наиболее зависимы от структуры исходного угля как предшественника СВУ. Очевидно, усложнение структуры нитропроизводных угля с метаморфизмом требует большей энергии для их разложения, что и вызывает сдвиг значений $\mathrm{T}_{3}$ в область низких температур, как показано на рис. 12.

Термодеструкция функциональных групп СВУ в соединении с вторичными конденсационными процессами (образование связей типа R-R, R-O-R $\mathrm{R}_{1}, \mathrm{R}-\mathrm{N}-\mathrm{R}_{1}$ ) формирует новый трехмерный макромолекулярный каркас. Существенно более высокая реакционная способность СВУ обусловлена термоинициированными реакциями структурных центров, введенных при модификации угля системой $\mathrm{HNO}_{3}-\mathrm{Ac}_{2} \mathrm{O}$.

\section{Образование СМС угля с гидроксидом калия}

Обработка угля либо СВУ гидроксидом калия осуществляется из водных растворов при температурах $\leq 100{ }^{\circ} \mathrm{C}$ [13]. Обязательным этапом выступает выдерживание образца заданное время в контакте с водным раствором КОН. Заключительный этап - удаление водной фазы при высушивании, когда образуются условия принудительного интеркалирования щелочи в угольный каркас. Результатом интеркалирования является образование СМС, что передается следующей схемой:

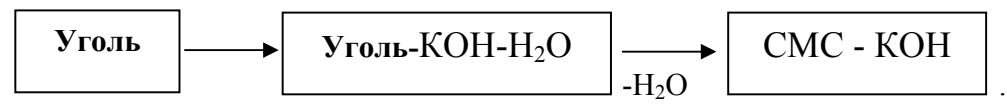

Иногда используют механическое смешение угля с твердой щелочью [37]. Если принять во внимание, что и уголь, и щелочь всегда содержат кристаллизационную воду, то механическое смешение отличается от приведенной схемы импрегнирования только весовым соотношением уголь $/ \mathrm{KOH} / \mathrm{H}_{2} \mathrm{O}$.

Взаимодействие угля с КОН включает следующие процессы и реакции.

1. Диффузия ионов $\mathrm{K}^{+}$и $\mathrm{OH}^{-}$в угольный каркас и их пространственное закрепление вблизи поляризованных С-С и С-О связей каркаса по аналогии с образованием ассоциатов. Количество поляризованных С-С связей в СВУ, очевидно, достаточно велико, потому что $\mathrm{NO}_{2}$-группа является электроноакцепторным заместителем. Щелочная обработка сопровождается набуханием СВУ и реорганизацией пространственного каркаса. Последняя наблюдается для угля, структурные фрагменты которого конформационно подвижны, поскольку связаны между собой нековалентными взаимодействиями или небольшим числом алифатических или кислородных мостиков. Например, интеркалирование $\left(\mathrm{R}_{\text {кон }}=0,56\right.$ г/г) бурого угля $\left(\mathrm{C}^{\text {daf }}=73,7 \%\right.$ в вызывает увеличение значений $\mathrm{d}_{002}\left(\mathrm{c} 0,412\right.$ до 0,489 нм), $\mathrm{L}_{\mathrm{C}}(\mathrm{c} 0,802$ до 1,515 нм), объема «кристаллитов» $\mathrm{V}_{\text {кр }}$ (с 1,3 до 2,0 нм³) и среднего числа слоев в «кристаллите» (с 3,0 до 4,5) [11].

2. Разрушение межмолекулярных нековалентных (водородных, электронодонорноакцепторных) связей с образованием новых связей в «СМС-КОН» при удалении воды после высушивания. Например, дополнительное количество межмолекулярных водородных связей в угольной решетке может образовываться при участии нитрогрупп по аналогии с водородными связями в твердом паранитрофеноле [38 ]: 
<smiles>O=[N+]([O-])c1ccc(O)cc1</smiles>

Межмолекулярные связи в СМС могут осуществляться за счет образования комплексов с переносом заряда (КПЗ), в которых нитроареновые фрагменты играют роль электроноакцептора при взаимодействии с алкилареновыми фрагментами в «кристаллите» (по аналогии с КПЗ нитроаренов с конденсированными ароматическиими углеводородами).

3. Реакции КОН с функциональными группами.

А) Образование фенолятов и карбоксилатов калия:

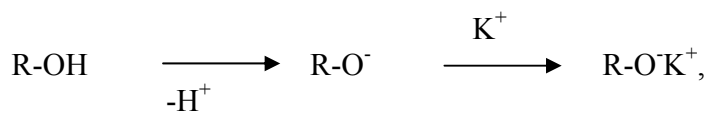

где $\mathrm{R}=\mathrm{Ar}, \mathrm{Ar}-\mathrm{C}(\mathrm{O})-$, $\mathrm{Alk}-\mathrm{C}(\mathrm{O})$-.

Как следствие такого рода реакций в ИК-спектрах аддуктов СМК с КОН, что видно на рис. 14 , исчезает полоса карбонильного поглощения $\left(1720 \pm 2 \mathrm{~cm}^{-1}\right)$ и появляются полосы поглощения асимметричных $\left(1579 \pm 2 \mathrm{~cm}^{-1}\right)$ и симметричных $\left(1388 \pm 2 \mathrm{~cm}^{-1}\right)$ валентных колебаний

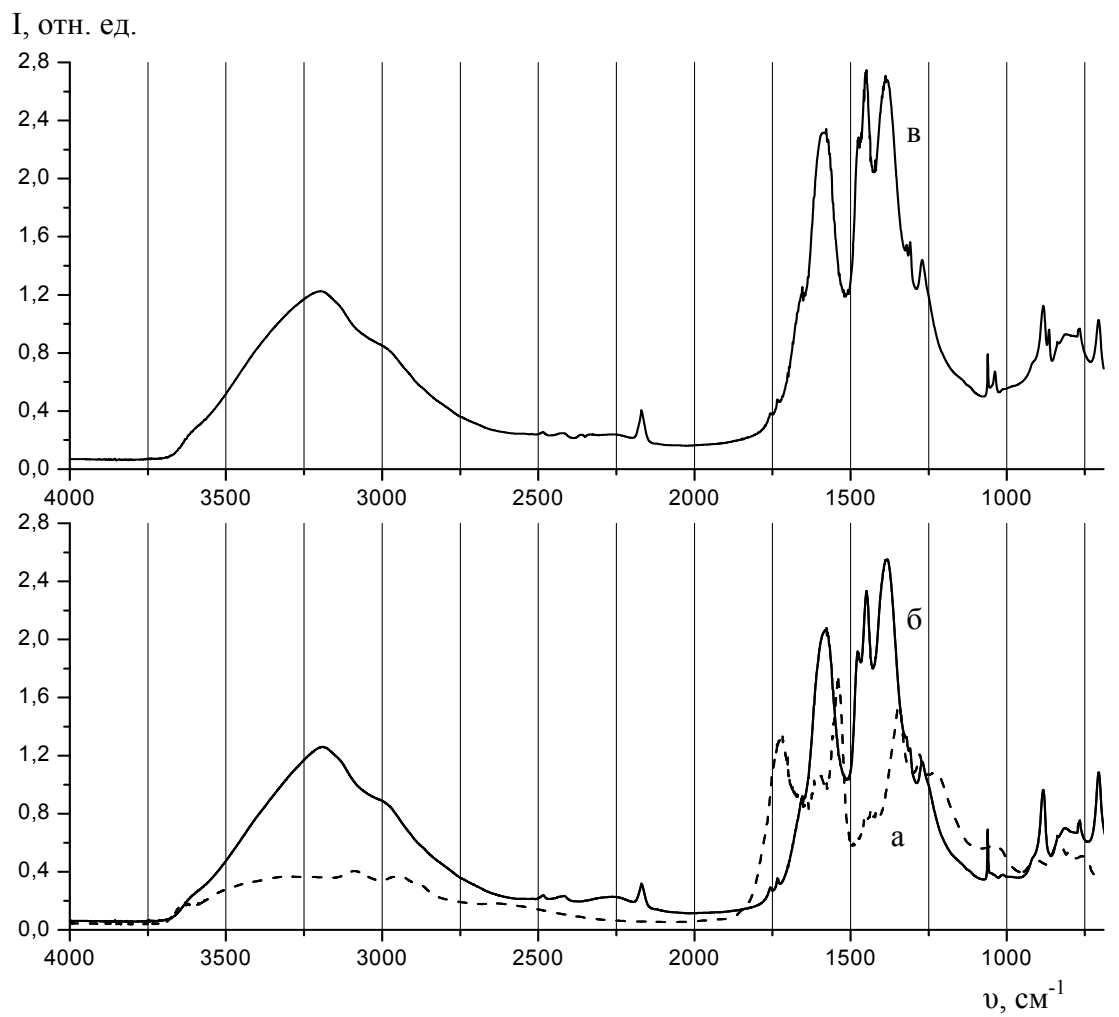

Рис. 14. ИК-спектры модифицированного угля марки ОС (C $\mathrm{daf}=90,0 \%): \mathrm{a}-\mathrm{CBУ} ; \sigma-\mathrm{CMC}-\mathrm{KOH}\left(\mathrm{R}_{\text {кон }}=1,0\right.$ г/г); в - СМС-КОН, прогретый при $180{ }^{\circ} \mathrm{C}(2$ ч) 
карбоксилатных групп. Этот процесс обратим, и после удаления КОН (соляной кислотой и водой) спектральная картина восстанавливается.

Качественно идентичные изменения происходят и при щелочной обработке гуминовых кислот [31], окисленных углеродных материалов [39] и отвечают изменениям в ИК-спектрах при образовании солей индивидуальных органических кислот [29].

Б) Расщепление сложноэфирных (в том числе лактонных) групп:

$$
\mathrm{Ar}-\mathrm{C}(\mathrm{O})-\mathrm{O}-\mathrm{Ar}_{1}+\mathrm{KOH} \rightarrow \mathrm{Ar}-\mathrm{C}(\mathrm{O})-\mathrm{O}^{-} \mathrm{K}^{+}+\mathrm{K}^{+} \mathrm{O}^{--} \mathrm{Ar}_{1}
$$

Реакции (2) и (3) приводят к частичной структурной фрагментаци органического каркаса СМК (по крайней мере, за счет разрыва сложноэфирных С-О-С-связей) с образованием калиевых солей нитрогуминовых кислот, которые можно выделить из СМК как самостоятельные продукты.

В) Переход нитросоединений СМК в ацинитросоединения.

Такие реакции хорошо известны для нитрофенолов [38]:

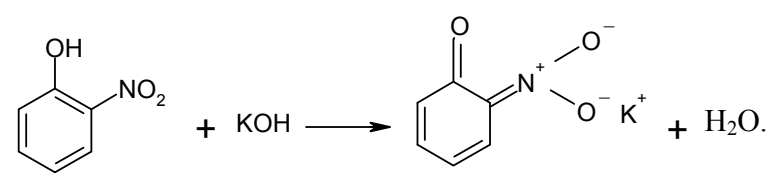<smiles>[Y][N+]([O-])([O-])C1C=CC(=O)C=C1</smiles>

Эти реакции смещаются вправо за счет удаления воды при высушивании СМС. В подтверждение образования калиевых солей ацинитросоединений в ИК-спектрах «СМС - КОН» исчезает полоса асимметричных $\left(1540 \mathrm{~cm}^{-1}\right)$ и симметричных $\left(1350 \mathrm{~cm}^{-1}\right)$ валентных колебаний

Кроме того, в спектрах появляются полосы поглощения хинонов $\left(1654 \mathrm{~cm}^{-1}\right)$ и наблюдается увеличение их интенсивности при нагревании до $180^{\circ} \mathrm{C}$. Необходимо отметить, что для реализации перехода по реакциям 17 и 18 в структуре СМС должен присутствовать донор подвижных Н-атомов. Им может быть как фенольная группа, так и любая С-Н кислотная функция:

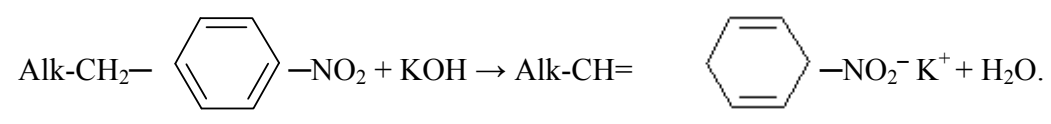

В твердой фазе (особенно при наличии в структуре угля конформационной подвижности отдельных структурных фрагментов) и сильного электронного взаимодействия (на уровне КПЗ) таких внутрикаркасных доноров Н-атомов может быть много.

Г) Реакции с участием радикалов. 
По данным метода ЭПР, для СВУ из угля $\mathrm{K}_{2}\left(\mathrm{C}^{\mathrm{daf}}=88,6 \%\right)$ при модификации смесью $\mathrm{HNO}_{3}-\mathrm{Ac}_{2} \mathrm{O}\left(\mathrm{R}_{\mathrm{ox}}=10-20\right.$ моль/кг) выявлено, что концентрация неспаренных электронов снижается (с 40·10 18 до $3,5 \cdot 10^{18} \Gamma^{-1}$ ), а после образования СМС с КОН увеличивается до $9,5 \cdot 10^{18} \Gamma^{-1}$, или в 2,7 раза [13]. Такой эффект обычно наблюдается при образовании семихинонных анионрадикалов [40] и характерен для гуминових кислот и низкометаморфизованных углей:<smiles>O=C1C=CC(=O)c2c(O)ccc(O)c21</smiles><smiles>[Y][X]C=C</smiles><smiles>[Y16]Oc1ccc(O)c2c([O+])ccc(O)c12</smiles>

Угольные радикалы также могут образовываться при генерации металл-кетилов [11]:

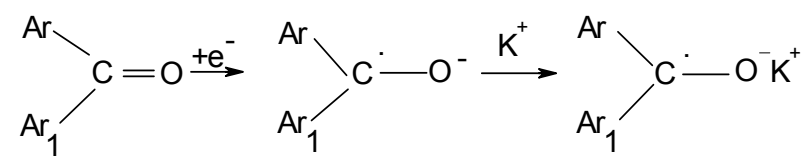

Судя по ИК-спектрам, в СМС есть сопряженные кетонные группы, а источником электронов могут служить структурные фрагменты СМС. Кроме того, внутрикаркасный катион $\mathrm{K}^{+}$ взаимодействует с угольным радикалом, что подтверждается влиянием природы катиона (при варьировании щелочей от $\mathrm{LiOH}$ до $\mathrm{CsOH}$ ) на характеристики спектров ЭПР угольных радикалов: ширину линии - $\Delta$ Н и величину g-фактора [11].

Можно предположить, что образование при импрегнировании дополнительного количества угольных радикалов, которые являются достаточно реакционными фрагментами, приведет к дополнительным радикальным маршрутам реакций, например радикальной полимеризаци при образовании вторичного макромолекулярного каркаса.

\section{Конверсия СМС с КОН в адсорбенты}

При нагревании «СМC-KOH» происходят термоинициированные реакции структурных фрагментов СМС с КОН [11].

1. Деструкция и образование кислород- и азотсодержащих функциональных групп.

Термолиз карбоксилатов, фенолятов и нитрофенолятов калия происходит в диапазоне температур $180-400{ }^{\circ} \mathrm{C}$ : в ИК-спектрах пропадают полосы поглощения колебаний карбоксилатных групп $\left(1579,1388 \mathrm{~cm}^{-1}\right)$. Карбоксилаты калия (-COO- $\left.{ }^{+}\right)$разрушаются с образованием $\mathrm{CO}_{2}$, взаимодействие которого с КОН дает $\mathrm{KHCO}_{3}$ (полоса при $1374 \mathrm{~cm}^{-1}$ ), который при дальнейшем нагревании переходит в $\mathrm{K}_{2} \mathrm{CO}_{3}$ (полоса при $1363 \mathrm{~cm}^{-1}$ ). Термолиз до $400{ }^{\circ} \mathrm{C}$ приводит к разрушению фрагментов $-\mathrm{NO}_{2} \mathrm{~K}^{+}$. Хиноны присутствуют до температуры $600{ }^{\circ} \mathrm{C}$ (полоса при $\left.1654 \mathrm{~cm}^{-1}\right)$. Кроме термодеструкции возможно образование фенолятных групп при дегидрировании угольных полиаренов $\left(350-600{ }^{\circ} \mathrm{C}\right)[41,42]$ :

$$
\begin{aligned}
& \mathrm{Ar}-\mathrm{H}+\mathrm{MOH} \rightarrow \mathrm{ArOM}+\mathrm{H}_{2}, \\
& \mathrm{Ar}-\mathrm{CH}_{2}-\mathrm{Ar}+\mathrm{MOH} \rightarrow \mathrm{ArCH}(\mathrm{OM}) \mathrm{Ar}+\mathrm{H}_{2} .
\end{aligned}
$$


2. Реакции щелочной деструкции каркасообразующих цепей.

Это гетеролиз эфиров, щелочная деструкция поляризованных С-C связей и расщепление О-содержащих гетероциклов. Полоса поглощения (1270 см-1) С-О- групп эфиров в ИК-спектрах продуктов термолиза при $400{ }^{\circ} \mathrm{C}$ исчезает. Деструкция алифатических $\mathrm{C}$-С-связей как в присутствии щелочи, так и без нее завершается до $600{ }^{\circ} \mathrm{C}$. Реакции расщепления С-О- и С-C-связей составляют процесс структурной фрагментаци каркаса до твердых и летучих продуктов термолиза. Выход последних при нагревании соединения «СМС-КОН» приблизительно в 1,5 раза выше, чем при нагревании исходного угля с КОН, поскольку кроме образования высокомолекулярных фрагментов разрушаются и функциональные группы СМС, практически отсутствующие в исходном угле.

3. Инициированные щелочью реакции образования вторичного макромолекулярного каркаса.

Формирование вторичной решетки происходит за счет поликонденсации и полимеризации, которые конкурируют со щелочной деструкцией органических цепей. Эти реакции достаточно разнообразны и приводят к отличию структур твердых продуктов активации СМС и угля: скелетные колебания $\mathrm{C}=\mathrm{C}$-связей проявляются при $1593 \mathrm{~cm}^{-1}(\mathrm{CMC})$ против $1580 \mathrm{~cm}^{-1}$ (уголь). Область поглощения фенолов и эфиров активатов СМС более интенсивна и проявляется при более высокой частоте $\left(1240 \mathrm{~cm}^{-1}\right)$, чем у активатов исходного угля $\left(1188 \mathrm{~cm}^{-1}\right)$. Адсорбенты из СМС содержат фрагменты с $\mathrm{C} \equiv \mathrm{N}$-связями $\left(2198 \mathrm{~cm}^{-1}\right)$ и отличаются степенью замещения ароматического водорода и различными заместителями в ароматических и эфироароматических фрагментах.

Набор вышеперечисленных реакций приводит к формированию активированного угля (AУ), свойства которого зависят от основных факторов процесса - времени $\left(\tau_{\mathrm{a}}\right)$, температуры $\left(\mathrm{t}_{\mathrm{a}}\right)$ и весового соотношения щелочь - уголь $\left(\mathrm{R}_{\mathrm{KoH}}\right)$. Зависимости изменений удельной поверхности $\left(\mathrm{S}_{\mathrm{BET}}\right)$ от $\tau_{\mathrm{a}}, \mathrm{t}_{\mathrm{a}}$ и $\mathrm{R}_{\mathrm{KoH}}$ установлены для $\mathrm{CMC}$ из угля марки $\mathrm{OC}\left(\mathrm{C}^{\mathrm{daf}}=90,0 \%\right)$, который проявляет максимальную способность интеркалироваться (рис. 15). Его пространственная структура реорганизуется значительно, хотя полиареновые фрагменты остаются практически незатронутыми; вклад нитрования в перестройку макромолекулярного каркаса максимален.

Зависимости величин $\mathrm{S}_{\mathrm{BET}}$ и выходов активатов $\left(\mathrm{Y}_{\mathrm{AB}}\right)$ от времени показывают, что АУ из «СМС-КОН» характеризуются более высокими значениями удельной поверхности (рис. 15). Величина поверхности интенсивно развивается в первые 0,5 ч, далее $(0,5-2$ ч) увеличивается медленно и при $\tau_{\mathrm{a}} \geq 2$ ч значения $\mathrm{S}_{\mathrm{BET}}$ в пределах ошибок постоянны. Стабильный виход активатов получен за 2 ч активации и далее практически не меняется. Соединение «СMC-KOH» образует АУ с более развитой поверхностью во всем диапазоне температур $\left(400-800{ }^{\circ} \mathrm{C}\right)$ (рис. 16). С увеличением температуры значения $\mathrm{S}_{\mathrm{BET}}$ растут, достигая максимальных значений при $\mathrm{t}_{\mathrm{a}}=800^{\circ} \mathrm{C}$.

Выходы АУ из «СМС - КОН» ниже, чем выходы твердых продуктов из исходного угля, и с ростом температуры $\left(400-800{ }^{\circ} \mathrm{C}\right)$ снижаются с 88 до $51 \%$ (уголь) и с 64 до $32 \%$ (CMC). Величина $\mathrm{S}_{\mathrm{BET}}$ зависит от соотношения КОН/уголь (табл. 3), и максимальные значения $\mathrm{S}_{\mathrm{BET}}$ достигаются при $\mathrm{R}_{\mathrm{KOH}}=30-60$ моль/кг. В этих условиях СМС активируется в углеродные материалы с развитой поверхностью (1500-2000 м²/г), тогда как поверхность АУ из исходного угля не превышает $200 \mathrm{M}^{2} /$. 

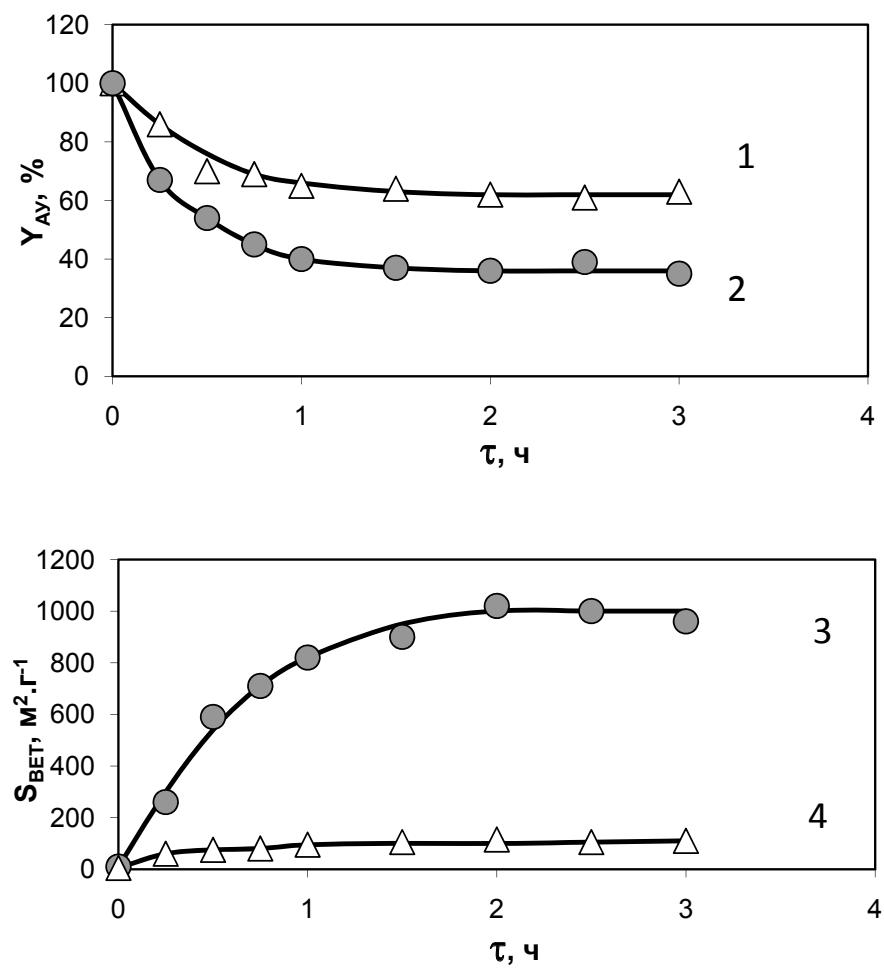

Рис. 15. Зависимости выхода $(1,2)$ и удельной поверхности $(3,4)$ активированного угля от времени активации угля $\mathrm{K}_{2}(1,4)$ и $\mathrm{CMC}(2,3): \mathrm{R}_{\text {кон }}=20$ моль'к $\Gamma^{-1} ; \mathrm{t}=800{ }^{\circ} \mathrm{C}$

Таким образом, низкотемпературное интеркалирование в системе $\mathrm{HNO}_{3}-\mathrm{Ac}_{2} \mathrm{O}$ повышает реакционную способность угля в процессе дальнейшей химической активации. Введенные при интеркалировании функциональные группы промотируют взаимодействие угольного каркаса со щелочью (способствуют образованию СМС-КОН), что при последующем нагревании вызывает дополнительные термоинициированные реакции с участием КОН, следствием которых является формирование пористого углеродного каркаса с высокоразвитой поверхостью.

\section{Выводы}

1. На основании данных об изменениях структуры и свойств углей разной степени метаморфизма в контакте с эквимолярной смесью $\mathrm{HNO}_{3}-\mathrm{Ac}_{2} \mathrm{O}$ установлено образование соединений включения угля, основным структурным элементом которых являются ионные пары катионов угля и интеркалированных ацетат-анионов.

2. Ключевыми процесами, контролирующими трансформацию угля в СВУ, выступают: образование органических катионов через стадию катион-радикалов вследствие переноса электронов с полиаренов на частицы $\mathrm{NO}_{2}{ }^{+}$, интеркалирование ацетат-анионов и их фиксация вблизи катионных структурных центров, химическая модификация угольного каркаса - группа реакций электрофильного ароматического замещения, окисления и оксидеструкции, которые ведут к образованию новых структурных фрагментв и функциональных групп. 

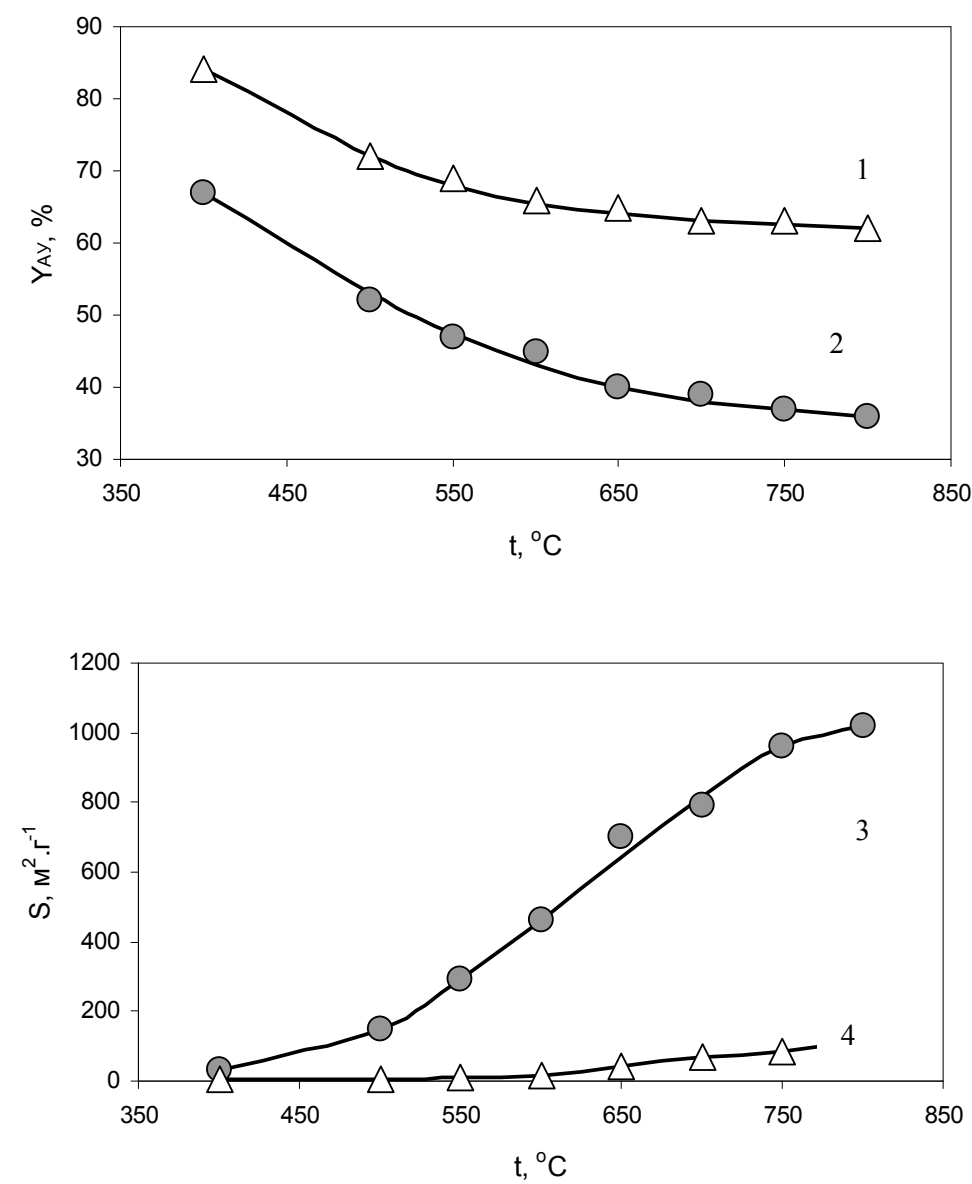

Рис. 16. Температурные зависимости выходов $(1,2)$ и удельной поверхности $(3,4)$ активированного угля из угля $\mathrm{K}_{2}(1,4)$ и СМК $(2,3): \mathrm{R}_{\text {кон }}=20$ моль Кг $^{-1} ; \tau_{\mathrm{a}}=2$ ч

Таблица 3. Выход и величина удельной поверхности продуктов активации угля $\mathrm{K}_{2}$ и СМС-КОН как функция соотношения $\mathrm{KOH} /$ уголь $\left(\mathrm{t}_{\mathrm{T}}=800^{\circ} \mathrm{C}, \tau=2\right.$ ч)

\begin{tabular}{|l|c|c|c|c|c|c|c|c|}
\hline \multirow{2}{*}{ Образец } & \multirow{2}{*}{ Параметр } & \multicolumn{9}{|c|}{$\mathrm{R}_{\text {кон }, \text { моль'кг-1 }}$} \\
\cline { 3 - 10 } & & 0 & 10 & 20 & 30 & 40 & 50 & 60 \\
\hline \multirow{2}{*}{$\mathrm{K}_{2}$} & $\mathrm{Y}_{\mathrm{Ay}}, \%$ & 81 & 70 & 62 & 52 & 51 & 48 & 46 \\
\cline { 2 - 10 } & $\mathrm{S}_{\mathrm{BET}}, \mathrm{M}^{2} \cdot \Gamma^{-1}$ & 6 & 84 & 115 & 140 & 150 & 180 & 190 \\
\hline \multirow{2}{*}{$\mathrm{CMC}$} & $\mathrm{Y}_{\mathrm{Ay}}, \%$ & 59 & 47 & 36 & 32 & 31 & 32 & 30 \\
\cline { 2 - 10 } & $\mathrm{S}_{\mathrm{BET}}, \mathrm{M}^{2} \cdot \Gamma^{-1}$ & 23 & 670 & 1020 & 1530 & 1900 & 1980 & 1890 \\
\hline
\end{tabular}

3. С ростом СМ способность угля образовывать СВУ изменяется экстремально с максимумом у угля $\mathrm{c}^{\mathrm{daf}}=87-90 \%$. Низкометаморфизованные угли более активны по отношению к электроноакцепторам, но доминирующим процессом является оксидеструкция. Интеркалирование антрацитов реализуется в поверхностном слое и не приводит к структурной реорганизации ароматических фрагментов каркаса. 
4. Установлены основные закономерности термолиза СВУ и их супрамолекулярных соединений с КОН, влияние на них СМ угля и концентрации щелочи. Определены физикохимические и структурные характеристики твердых продуктов термолиза.

5. При термообработке $\left(800{ }^{\circ} \mathrm{C}, 2\right.$ ч) супрамолекулярные соединения угля с $\mathrm{KOH}$ $\left(\mathrm{R}_{\text {кон }}=30-60\right.$ моль/кг) превращаются в высокопористые материалы $\left(1500-2000 \mathrm{M}^{2} \cdot \Gamma^{-1}\right)$.

\section{Список литературы}

1. Лен Ж.-М. Супрамолекулярная химия: концепции и перспективы / пер. с англ. Новосибирск: Наука, 1998. 334 с. [Lehn J.-M. Supramolecular Chemistry: Concepts and Perspectives. Weinheim: VCH, 1995].

2. Iino M. Higher order structures of coal and their influence on coal reactivity // Energy \& Fuels. 2002. Vol. 16(1). P. 1-2.

3. Marzec A. Towards an understanding of the coal structure: a review // Fuel Processing Technology 2002. Vol. 77-78. P. 25-32.

4. Шендрик Т.Г., Саранчук В.И. Соленые угли. Донецк: Східний видавн. дім, 2003. $296 \mathrm{c}$.

5. Рудаков Е.С., Кучеренко А.В. Соединения внедрения ископаемых углей с щелочными металлами, металлокомплексами, кислотами Льюиса и Бренстеда // Физико-химические свойства угля: сб. науч. тр. Киев: Наукова думка, 1992. С. 136-151. [Rudakov E.S., Kucherenko A.V. Intercalation compounds coals with alkali metals, metal complexes, Lewis and Bronsted acids. Physical and chemical properties of coal. Book of Scientific Papers. Kiev: Naukova Dumka, 1992. P. 136-151. (In Russ.)].

6. Chung D.D.L., Woychik C.G., Searching the evidence for the intercalation of bromine in high rank coal // Fuel. 1987. Vol. 66(6). P. 799-802.

7. Daulan C., Lyubchik S.B., Rozaud J.-N., Beguin F. Influence of anthracite pretreatment on the preparation of activated carbons // Fuel. 1998. Vol. 77(6). P. 495-502.

8. Lyubchik S.B., Benoit R., Beguin F. Influence of chemical modification of anthracite on the porosity of the resulting ACs // Carbon. 1996. Vol. 34(1), P. 1329-1334.

9. Albiniak A., Furdin G., Beguin D., Mareche J.F., Kaczmarczyk J., Broniek E. Exfoliaton and textural modification of anthracites // Carbon. 1996. Vol. 34(1). P. 1329-1334.

10. Furdin G. Exfoliation process and elaboration of new carbonaceous materials // Fuel. 1998. Vol. 77(6). Р. 479-485.

11. Кучеренко В.А., Зубова Т.И. Образование и термолиз соединений включения угля гидроксидами щелочных метал лов // Журнал общей химии. 1995. Т. 65(8). С. 1256-1264. [Kucherenko V.A., Zubova T.I. Formation and thermolysis of inclusion compounds of coal by alkali metal hydroxides. Russian Journal of General Chemistry 1995. Vol. 65(8). P. 1256-1264. (In Russ.)].

12. Кучеренко В.А., Сапунов В.А., Зубова Т.И., Чуприна В.С., Зайковский А.В. Термолиз импрегнированного щелочами бурого угля // Химия твердого топлива. 1992. № 4. С. 96-101. [Kucherenko V.A., Sapunov V.F., Zubova T.I., Chuprina V.S., Zaikovsky A.V. Thermolysis of brown coal impregnated by alkali. Solid Fuel Chemistry 1992. N 3. P. 96-101. (In Russ.)]

13. Кучеренко В.А., Хабарова Т.В., Чотий К.Ю. Окисление природного угля ацетилнитратом как первая стадия получения углеродных адсорбентов и гуминовых кислот // Журнал 
прикладной химии. 1996. Т.69(9). C. 1462-1467. [Kucherenko V.A., Khabarova T.V., Chotii K.Yu. Oxidation of natural carbon by acetyl nitrate as the first step in the preparation of carbon adsorbents and humic acids. Russian Journal of Applied Chemistry. 1996. Vol. 69(9). P. 1462-1467. (In Russ.)].

14. Bodoev N.V., Gruber R., Kucherenko V.A., Guet J.-M., Khabarova T.V., Cohaut N., Heintz O., Rokosova N.N. A novel process for preparation of active carbon from sapropelitic coals // Fuel. 1998. Vol. 77(6). P. 473-478.

15. Kucherenko V.A., Gruber R., Popov A.F., Duber S., Zubova T.I., Khabarova T.V. Active carbon from anthracite: influence of pre-oxidation resembling intercalation. Ext. abstracts of the Int. Carbon conf., Newcastle (UK), 7-12 July, Newcastle, 1996. Vol. 2. P. 407-408.

16. Черныш И.Г., Карпов И.И., Приходько Г.П., Шай В.М. Физико-химические свойства графита и его соединений. Киев: Наук. думка, 1990. 220 с. [Chernysh I.G., Karpov I.I., Prikhodko G.P., Shai V.M. Physicochemical properties of graphite and its compounds. Kiev: Naukova Dumka, 1990. 220 c. (In Russ.].

17. Химия комплексов «гость-хозяин». Синтез, структуры и применения / пер. с англ. М.: Мир, 1988. 511 с. [Host Guest Complex. Chemistry Macrosycles. Synthesis. Stracture. Application. Eds. F. Vogtle, E. Weber. Berlin, Heidelberg, New York, Tokio: Springer-Verlag, 1988. 511 c.].

18. Бодоев Н.В., Кучеренко В.А., Шендрик Т.Г., Бальбурова Т.А. Активированные угли из химически модифицированных сапропелитов // Журнал прикладнойхимии. 2004. Т. 77(5). С. 754 759. [Bodoev N.V., Kucherenko V.A., Shedrik T.G., Bal'burova T.A. Activated carbons prepared from chemically modified sapropelites // Russian Journal of Applied Chemistry 2004. Vol. 77(5). P. 750755.]

19. Тамаркина Ю.В., Шендрик Т.Г., Кучеренко В.А. Окислительная модификация ископаемых углей как первая стадия получения углеродных адсорбентов // Химия твердого топлива. 2003. T. 37(5). C. 38-50. [Tamarkina Yu.V., Shendrik T.G., Kucherenko V.A. Oxidative modification of fossil coals as the first stage of production of carbonaceous adsorbents // Solid Fuel Chemistry 2003. Vol. 37(5). P. 34-46].

20. Kucherenko V.A. Intercalation compounds formation in reactions of coals with acetylnitrate. Proc. $7^{\text {th }}$ Int. Conf. Coal Science. 1993. Vol. 2. P. 458-461.

21. Kucherenko V.A., Zubova T.I., Khabarova T.I. Low temperature conversion of coals through intercalation in nucleophilic reactions. Coal Science. - Amsterdam: Elsevier Science B.V., 1995. Vol. 1. P. $865-868$.

22. Кучеренко В.А., Чотий К.Ю., Зубова Т.И., Гребенюк Л.В., Хабарова Т.В. Окисление природного угля в системе $\mathrm{HNO}_{3}$-уксусный ангідрид // Журнал общей химии. 1996. Т. 66(6). C. 888-893. [Kucherenko V.A., Chotii K.Yu. Zubova T.I., Grebenyuk L.V., Khabarova T.V. The oxidation of coal in a natural system $\mathrm{HNO}_{3}$-acetic anhydride // Russian Journal of General Chemistry. 1996. Vol. 66(6). P. 888-893. (In Russ.)]

23. Тамаркина Ю.В., Шендрик Т.Г., Кучеренко В.А. Взаимодействие углей различной степени метаморфизма в реакции с ацетилнитратом // Химия твердого топлива. 2001. Т. 35(4). C. 38-44. [Tamarkina Yu.V., Shendrik T.G., Kucherenko V.A. Reaction of coals of various ranks with acetyl nitrate. Solid Fuel Chemistry 2001. Vol. 35(4). P. 34-40].

24. Кучеренко В.А., Лобачев В.Л., Зубова Т.И., Хабарова Т.В. Взаимодействие длиннопламенного угля с ацетилнитратом // Химия твердого топлива. 1993. № 4. С. 19-25. [Kucherenko V.A., 
Lobachev V.L., Zubova T.I., Khabarova T.V. Interaction of long-flame coal with acetyl nitrate. Solid Fuel Chemistry 1993. N 4. P. 19-25. (In Russ.)].

25. Зверев И.В., Тутинас В.А., Долгова М.О., Соболева Д.В. Метод расчета структурных параметров углей. Прогноз и предотвращение опасных газопроявлений при разработке угольных месторождений. М.: ИПКОН АН УССР, 1990. С. 14-19. [Zverev I.V., Tutinas V.A., Dolgova M.O., Soboleva D.V. Method for calculating the structural parameters of coal. Prognosis and prevention of dangerous gas shows in the development of coal deposits. Moscow: IPKON AN USSR, 1990. P. 14-19.].

26. Саранчук В.И., Айруни А.Т., Ковалев К.Е. Надмолекулярная структура и свойства угля. Киев: Наукова думка, 1988. 192 с. [Saranchuk V.I., Airuni A.T., Kovalev K.E. Above molecular structure and properties of coal. Kiev: Naukova Dumka, 1988. 192 p. (In Russ.)].

27. Tamarkina Y.V., Shendrik T.G., Krzton A., Kucherenko V.A. Reactivity and structural modification of coals in $\mathrm{HNO}_{3}-\mathrm{Ac}_{2} \mathrm{O}$ system // Fuel Processing Technology. 2002. № 7778. P. $9-15$.

28. Кучеренко В.А., Тамаркина Ю.В., Шендрик Т.Г. Реорганизация структуры природных углей в системе $\mathrm{HNO}_{3}-\mathrm{Ac}_{2} \mathrm{O} / /$ Углехимический журнал. 2004. № 3-4. C. 3-11. [Kucherenko V.A., Tamarkina Yu.V., Shendrik T.G. Reorganization of the structure of natural coals by a mixture of $\mathrm{HNO}_{3}$ $\mathrm{Ac}_{2} \mathrm{O}$. Uglekhimicheskii zhurnal 2004. N 3-4. P. 3-11. (In Russ)].

29. Bellamy J.L. The infrared spectra of complex molecules. London: Chapman and Hall Ltd, third edition, 1975. $433 \mathrm{p}$.

30. Wang S.-H., Griffits P.R. Resolution enhancement of diffuse reflectance i.r. spectra of coals by Fourier self deconvolution. 1. C-H stretching and bending modes // Fuel. 1985. Vol. 64(2). P. 229-236.

31. Орлов Д.С., Осипова Н.Н. Инфракрасные спектры почв и почвенных компонентов. М.: Изд-во Моск. ун-та, 1988. 89 с. [Orlov D.S., Osipova N.N. Infrared spectra of soils and soil components. Moscow: Moscow University, 1988. 89 p. (In Russ.)].

32. Zavadski J. Infrared spectroscopy in surface chemistry of carbons // Chemistry and physics of carbon. New York: Marcel Dekker, 1989. Vol. 21. P. 147-380.

33. Кучеренко В.А., Хабарова Т.В., Тамаркина Ю.В. Активность природного угля в реакциях нитрования // Украинский химический журнал. 1999. Т.65(4). С. 124-129. [Kucherenko V.A., Khabarova T.V., Tamarkina Yu.V. Activity of natural coal in the nitration reaction. Ukrainskii khimicheskii zhurnal 1999. Vol. 65(4). P. 124-129. (In Russ.)].

34. Кучеренко В.А. Нитрование природного угля в системах $\mathrm{HNO}_{3}-\left(\mathrm{CH}_{3} \mathrm{CO}\right)_{2} \mathrm{O}$ и $\mathrm{HNO}_{3}$ $\left(\mathrm{CF}_{3} \mathrm{CO}\right)_{2} \mathrm{O} / /$ Структура органических соединений и механизмы реакцій: сб. науч. тр. Донецк: Компьютер норд, 1998. С. 73-79. [Kucherenko V.A. Nitration of natural coal in the systems $\mathrm{HNO}_{3}-\left(\mathrm{CH}_{3} \mathrm{CO}\right)_{2} \mathrm{O}$ and $\mathrm{HNO}_{3}-\left(\mathrm{CF}_{3} \mathrm{CO}\right)_{2} \mathrm{O}$. The structure of the organic compounds and the reaction mechanisms. Book of scientific papers. Donetsk: Komputer nord, 1998. P. 73-79. (In Russ.)].

35. Тамаркина Ю.В., Шендрик Т.Г., Галушко Л.Я., Кучеренко В.А. Термолиз ископаемых углей, модифицированных в системе $\mathrm{HNO}_{3}-\mathrm{Ac}_{2} \mathrm{O} / /$ Химия твердого топлива. 2002. № 4. С. $57-$ 65. [Tamarkina Yu.V., Shendrik T.G., Galushko L.Ya., Kucherenko V.A. Thermolysis of fossil coals modified by a mixture of $\mathrm{HNO}_{3}$ and $\mathrm{Ac}_{2} \mathrm{O}$. Solid Fuel Chemistry 2002. Vol. 36(4). P. 49-57.].

36. Накамото К. Инфракрасные спектры неорганических и координационных соединений: пер.с англ. М.: Мир, 1991, 536 с. [Nikamoto K. Infrared and Raman Spectra of Inorganic and 
Coordination of Inorganic and Coordination Compounds. New York, Chichester, Brisbane, Toronto, Singapure: Jon Wiley and Sons, 1986.].

37. Lillo-Rodenas M.A., Cazorla-Amoros D., Linares-Solano A. Understanding chemical reactions between carbons and $\mathrm{NaOH}$ and $\mathrm{KOH}$. An insight into the chemical activation mechanism // Carbon. 2003. Vol. 41(2). P. 267-275.

38. Несмеянов А.Н., Несмеянов Н.А. Начала неорганической химии. М.: Химия, 1974. Кн. 2. 744 c. [Nesmeyanov A.N., Nesmeyanov N.A. Beginning of Inorganic Chemistry. Moscow: Khimiya, 1974. Vol. 2. 744 p. (In Russ.)].

39. Mul J. Kapteijn F., Moulijn J.A. A DRIFTs study of the interaction of alkali metal hydroxides with carbonaceous surfaces // Carbon. 1999. Vol. 37(3). P. 401-140.

40. Steelink C. EPR studies of humic acid and related model compounds. Coal Science: Adv. chem. ser. Washington: ACS, 1966. Vol. 55. P. 80-90.

41. Yoshizawa N., K. Maruyama, Y. Yamada, E. Ishikawa, M. Kobayashi, Y. Toda, M. Shiraishi XRD evaluation of KOH activation process and influence of coal rank // Fuel. 2002. Vol. 81(5). P. 17171722.

42. Lillo-Rodenas M.A., Juan-Juan J., Cazorla-Amoros D., Linares-Solano A. About reactions occurring during chemical activation with hydroxides // Carbon. 2004. Vol. 42(7). P. 1371-1375. 